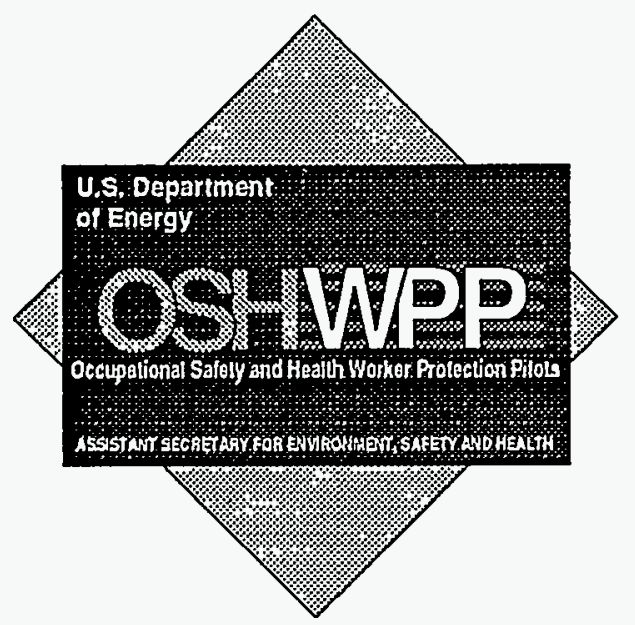

\title{
OSHWPP \\ Model Programs \\ Guide
}

Office of Safety and Quality Assurance

\section{Office of Occupational Safety and Health Policy}

\section{Personnel Protection Division}

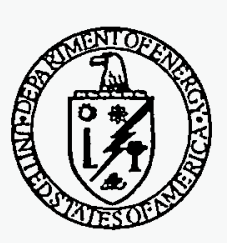

DISTRIBUTION OF THIS DOCUMENT IS UNLIMITED

U.S. Department of Energy

Washington, D.C. 20585

MASTER

June 1995 


\section{DISCLAIMER}

This report was prepared as an account of work sponsored by an agency of the United States Government. Neither the United States Government nor any agency thereof, nor any of their employees, make any warranty, express or implied, or assumes any legal liability or responsibility for the accuracy, completeness, or usefulness of any information, apparatus, product, or process disclosed, or represents that its use would not infringe privately owned rights. Reference herein to any specific commercial product, process, or service by trade name, trademark, manufacturer, or otherwise does not necessarily constitute or imply its endorsement, recommendation, or favoring by the United States Government or any agency thereof. The views and opinions of authors expressed herein do not necessarily state or reflect those of the United States Government or any agency thereof. 


\section{DISCLAIMER}

Portions of this document may be illegible in electronic image products. Images are produced from the best available original document. 
Foreword V

Asbestos Management (Sandia National Laboratories—Albuquerque) .......................................... 1

Chemical Management System (Battelle Pacific Northwest Laboratory) ..........................................5 5

Confined Space Entry (Martin Marietta Energy Systems-Oak Ridge K-25 Site) ............................ 9

Electrical Safety (Sandia National Laboratories_-corporatewide) .................................................. 13

Electrical Safety (Westinghouse Savannah River Company—Savannah River Site)............................. 17

Hazard Communication (Lockheed Idaho Technologies Company-Idaho National

Engineering Laboratory)

Hazardous Energy Control for Personnel Protection (Lockout/Tagout)

(Martin Marietta Energy Systems-Oak Ridge Y-12 Plant) .................................................................. 25

Hazardous Waste Training(Sandia National Laboratories_-Livermore) ......................................... 29

Hearing Conservation (Martin Marietta Energy Systems-Oak Ridge Y-12 Plant).......................... 33

Laboratory Standard Program (Sandia National Laboratories-corporatewide) ................................ 37

Lockout/Tagout —Control of Hazardous Energy (Argonne National Laboratory-East) ................... 41

Requirements Awareness Program (Lockheed Idaho Technologies Company-

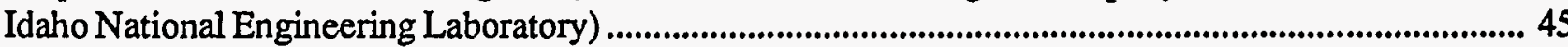

Respiratory Protection (Martin Marietta Energy Systems-Oak Ridge Y-12 Plant) ......................... 49

Site Safety Meetings (Westinghouse Savannah River Company-Savannah River Site) ....................... 53

Stretching (Extend Yourself) (Lockheed Idaho Technologies Company-

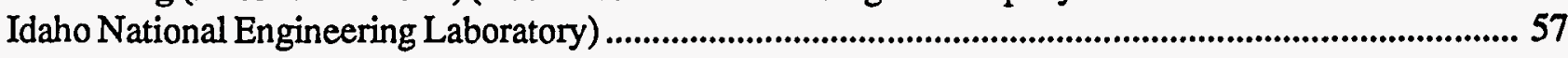

Video Display Terminal Worker Safety (Brookhaven National Laboratory) ..................................... 61

Work in Thermally Hot Environments (Lockheed Idaho Technologies CompanyIdaho National Engineering Laboratory)

Appendix: OSHWPP Model Program Evaluation Criteria

Notes 


\section{FOREWORD}

$\mathrm{O}$ ne of the most cost-effective ways to improve worker safety and health is to identify U.S. Department of Energy (DOE) model safety and health programs and transfer them-in their entirety or in part- to other sites. With this goal in mind, in 1992 the Department's Office of the Assistant Secretary for Environment, Safety and Health (EH) established the Occupational Safety and Health Worker Protection Pilots (OSHWPP). OSHWPP serves as a clearinghouse for model safety and health programs developed at the Department's Government-owned, contractor-operated (GOCO) facilities-programs that, by virtue of their excellence, offer the potential to shorten implementation time, reduce operating cost, and increase effectiveness when adopted by another DOE facility.

In November 1992, an announcement was distributed to the Department's field offices and major GOCO sites, saying, in effect, 'If your site has developed a safety or health program worthy of sharing, send a comprehensive description to the Office of Occupational Safety, the EH Office's OSHWPP sponsors.' Model program descriptive information was requested in eight categories:

1. Origin and purpose-How and why was your program created? (This information is intended as an introduction.)

Categories 2 through 6 were adopted from the Department of Labor's Voluntary Protection Program, developed by Labor's Occupational Safety and Health Administration (OSHA) and now an important DOE safety initiative sponsored by the Office of Occupational Safety and Health Policy.

2. Policies and procedures-How, exactly, does your program function?

3. Management commitment-How has management shown that it is committed to your program's success?
4. Employee involvement-How have employees been involved in your program's development, testing, operation, and improvement?

\section{Training-What training is required?}

6. Hazard abatement and control-How are hazards identified? How are they ameliorated?

7. Resources-What personnel, equipment, and funding were needed to bring your program into existence? to sustain it? (Category 7 was added to the list because DOE wants to publicize programs that provide a high level of safety or health effectiveness for each dollar spent.)

8. Points of contact-Whom can one call to leam more about your program?

In response to the 1992 announcement, 34 program descriptions were submitted for consideration as model programs. These submittals were assessed against OSHWPP criteria, a copy of which can be found in the appendix. Of the 34,17 scored at least 80 out of a possible 100 points, earning a rating of "Outstanding." Four of these outstanding programs were selected to be piloted, each at a facility that had volunteered to be a pilot site.

During the 7-month pilot phase, the principals who had created the model program worked closely with their pilot site counterparts to transfer either the entire program, as was the case for the chemical management system, or mutually agreed-upon selected features, as was the case for the other three piloted programs. The pilot phase formally culminated in February 1994, when the participants from each pair of sites met at a closeout and recognition meeting. (Note that some technology transfer continued past this date on features that had not yet been fully implemented.) Shortly thereafter, in the spring and early summer of 1994, the OSHWPP program office conducted four 1-day workshops-one for each model program - to describe the programs, their features, and the process by which they had been adopted by the pilot site. 
At the workshops, attendees heard detailed descriptions of the model programs presented by the model sites' key safety or health professionals. These experts included managers, the overall program coordinator, technical specialists, trainers, and computer experts (if the program involved a database). In addition, the pilot site representatives described how they adopted selected features by using the comprehensive program descriptions and the help that had been provided during the 7 months, both in person and by telephone, by their model program counterparts.

At a typical workshop, some 40 individuals attended

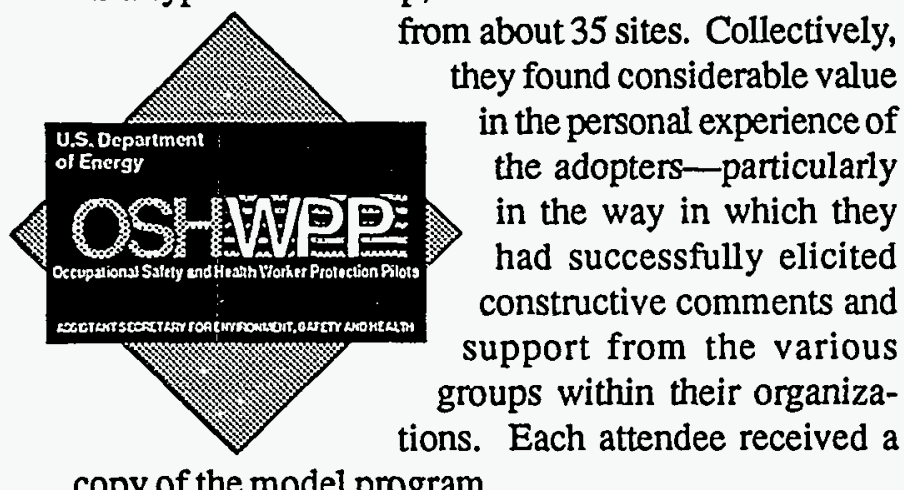
copy of the model program.

While the workshops helped disseminate to a larger audience what an OSHWPP model program could offer, the sponsoring office wished to further disseminate information about the 4 programs piloted and the 13 other outstanding programs not yet piloted. In compiling this guide of 17 summaries, each about 3 pages long, and distributing it widely throughout the DOE community, we hope to reach the largest audience, and in doing so, through emulation, effect a significant improvement in DOE worker safety and health. If a summary is of interest, readers are encouraged to request the comprehensive program description. Complete information regarding points of contact is found at the end of each summary. Readers are also encouraged to distribute the individual summaries or the entire guide to other interested managers and safety professionals.

To obtain information about any model programs, call the OSHWPP Program Manager (301/903-3972) and request a copy of the three-ring-bound, comprehensive program description. Most of the programs explain how they meet the OSHWPP criteria, with the sections on policy and procedures and training generally being the most detailed. You are encouraged to copy the binder's contents and distribute the copies to others. If you prefer, you may request additional three-ring-bound program descriptions.

More than half of the model programs are mandatorythat is, they are required by DOE Orders or Federal regulation. The remainder, such as the physical fitness and requirements-awareness programs (both developed at the Idaho National Engineering Laboratory) exemplify a "best practice."

EH continues to welcome model program participants. GOCO sites that have developed an exemplary health or safety program are invited to call the OSHWPP Program Manager to leam how to have it considered as a model during the next announcement cycle. Sites wishing to consider piloting a program developed at another site are likewise encouraged to call. As additional outstanding model programs are received, the guide will be expanded accordingly so that eventually it will serve as a truly comprehensive reference for all outstanding safety or health programs developed by DOE and its contractor organizations. 


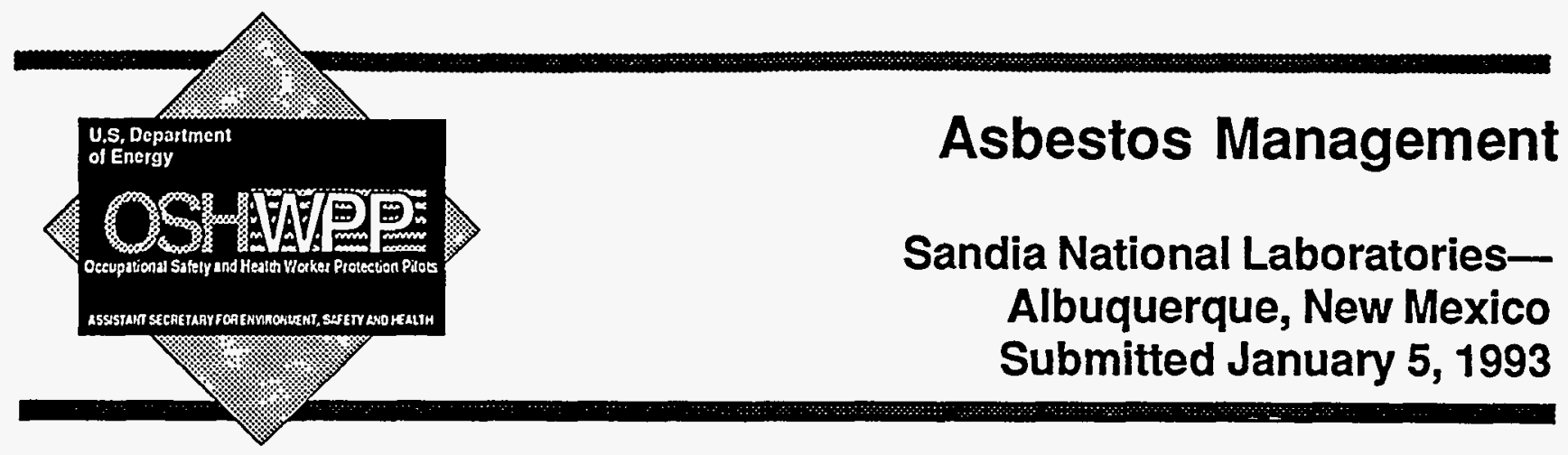

In response to Department of Energy (DOE) Draft Order 5480.10, which was issued in 1988 to inform DOE community members of their responsibilities regarding the control of asbestos, Sandia National Laboratories (SNL), Albuquerque, developed and implemented the Facilities Asbestos Management Program (FAMP). An Asbestos Management Team (AMT) was created to manage this and two other asbestos management programs which SNL had developed in response to specific organizational needs. These three programs were consolidated in 1992 to form the Sandia Asbestos Management Program (SAMP). Its key elements are survey/assessment, abatement, program development, records management, training, immediate response, and project management.

The goal of the program is to protect employees and the public from the adverse health effects of asbestos, which is present in almost all of the 1,100 buildings at SNL.

The SAMP Manual of Practice (MOP) is the primary document describing the SAMP and has been updated to reflect regulatory changes. A copy of the $M O P$ can be found in the comprehensive program description, along with supporting documentation. It describes the goals, implementation processes, procedures, and organizational structure related to the total management of asbestos at SNL.

The MOP provides decision flowcharts to guide the responsible person through situations where asbestos may be released into the ambient air. Within the program are several checkpoints and constraints to avoid incidental releases of this carcinogenic material.

The program also contains copies of employee news bulletins, training materials, and technical specifications. These documents are excellent references for expanding and implementing asbestos control programs at other sites.

The SAMP has been evaluated as being exemplary. It is recommended for adaptation or adoption by any DOE facility or site that has an asbestos concern.

Program Summary 


\section{Policies and Procedures}

\section{Management Commitment}

Asbestos is managed in place, as recommended by the U.S. Environmental Protection Agency, and will be removed if its presence and condition create a potential health hazard or if maintenance or modifications require that it be disturbed. Personnel will not be relocated in response to asbestos concems unless there is a likelihood of exceeding regulatory exposure limits. Responsibilities for implementing this policy are clearly defined, and all employees are aware of the potential hazard of asbestos exposure. The policy is in SNL's Environmental Safety and Health Manual, which is issued to all supervisors. They in turn are responsible for informing their personnel.

Detailed flowcharts and accompanying narratives describe the procedures to be followed in varying circumstances. To support the SAMP procedures, the model program also includes a detailed budget, an explanation of the program vision, the organizational structure, and personnel qualifications and training requirements.

Consequences for violating the program include monetary penalties for contractor negligence. The program features procedures designed to reduce or eliminate the potential for violation of requirements, including preconstruction walkthroughs, worksite inspections, and air monitoring.

The SAMP is managed through the Facilities ES\&H (Environment, Safety and Health) Program Management Department. The asbestos program implementation manager is a member of the Facilities Development Center. Industrial Hygiene supports the program by assigning a dedicated individual.

Management has demonstrated its commitment by chartering the SAMP, appointing an asbestos program manager, and funding the program. Its commitment to employees is manifested by the extensive educational program designed to enhance awareness. Additional training is presented on an as-needed or as-requested basis.

Management also enforces discipline with contractors and employees, documents walk-throughs of construction activities, and annually evaluates this program.

The AMT consists of employees from seven departments. AMT members and others with specific expertise regularly upgrade the program to keep pace with awareness and regulatory changes. The AMT also surveys buildings, locates asbestos-containing materials, distributes survey results, and initiates operations and maintenance plans.

At several junctures during the program process, employee feedback is solicited. Feedback from incident analyses and comments from training program participants are also used to improve the SAMP. 
Training under this program begins with general awareness for all employees. It is supplemented with specific training to meet the regulatory and SNL requirements. The training extends beyond asbestos to meet the additional potential hazards that are identified in the program's Preliminary Hazard Assessments (PHA's). Training matrices are in Section 7 of the MOP.

An Asbestos Control System database maintains the training records and warns of pending lapses of certification. This is supported by a hardcopy file maintained by the AMT in employee personnel files. Training is also kept current by internal presentations of technical specifications, brown-bag seminars, and bimonthly AMT meetings.

Engineering control practices are incorporated into the SNL Technical Specification Asbestos Abatement and Renovations. Task-specific hazards, identified in the PHA, are incorporated into the preliminary job assignments and work plans by the project manager. These are reviewed by a health and safety professional.

The use of personal protective equipment is addressed in the technical specification. At SNL, it is required more frequently than the regulations would indicate.

The SAMP initially was staffed and developed totally by using present personnel. As it grew, an asbestos technical consultant was retained. All positions identified in the SAMP require dedicated personnel. These positions may be filled by reorganizing the current staff, or additional personnel may need to be hired by the parent organizations.

Material resources are detailed in the $M O P$ and consist primarily of encapsulation, enclosure, and surface-cleaning supplies.

For a three-ring-bound, comprehensive description of this model program, call Ed Patigalia, OSHWPP Program Manager, U.S. Department of Energy, EH-51, at (301) 903-3972.

For answers to specific questions about SNL's Asbestos Management Program, call Gerald (Gerry) Lipka, Model Program Principal Contact, at (505) 844-5306.

For additional information about this model program, call Roy Lybarger, U.S. Department of Energy-Kirtland Area Office, at (505) 845-4342.

\section{Training}

\section{Hazard Abatement and Control}

\section{Resources}

\section{Points of \\ Contact}




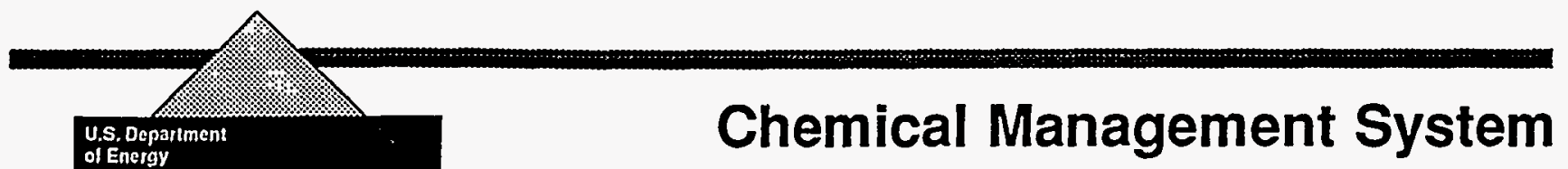

Battelle Pacific Northwest Laboratory Submitted December 11, 1992

The Chemical Management System (CMS) was developed at Battelle Pacific Northwest Laboratory (PNL), Richland, WA, as a computerized system designed to meet the chemical management and related regulatory needs of PNL, laboratorywide. The objectives of the CMS are threefold: provide a detailed inventory of the more than 100,000 containers of chemicals stored at PNL; ensure compliance with all healthand safety-related regulations; and allow management and staff to plan and control the purchase and storage of chemicals in a way that is at once efficient and environmentally sound.

Because the modules are linked to one another and to other key information systems, the CMS can minimize waste by permitting the facility to be searched before additional supplies of a chemical are ordered. If the chemical is found in the inventory, the purchase can be postponed and supplies transferred between locations.

The barcode-based inventory tracking, purchasing, and hazard management functions of the CMS are designed for ease of use and system flexibility, attributes that will make it easy to implement similar systems at other sites. Also, PNL is considering the development of a PC-based version, which would allow the information to be transferred to spreadsheets, databases, and word processors while making the system easier to use in organizations whose chemical management needs cannot justify full-time computer-support personnel.

The CMS generates more than 150 reports. These, in turn, are used to ensure regulatory compliance and to aid in hazard communication, training, and inventory management. All purchase orders are generated using the CMS; to ensure even tighter control, all sample materials provided by outside colleagues and vendors must be entered into the CMS by the user. Armed with this comprehensive gatekeeping policy, management can control the flow of chemicals throughout PNL.

When generating inventory reports, users can ask the CMS to print out a list of only those chemicals meeting specific criteria-for example, chemicals kept in a certain lab, bearing certain names, and meeting a particular hazardous group classification. In this way, for example, a manager can quickly identify differences between inventory records and physical inventories.

\section{Program \\ Summary}


As the purchasing module feeds the purchasing system, it establishes an inventory record for the item. The CMS manager receives reports listing all proposed purchases of items for which PNL has no Material Safety Data Sheet (MSDS). To ensure that the inventory records are consistent, this module also features error correction. Each record describes the chemical's properties, including threshold limit values and short-term exposure limits, and associates the chemical with one or more hazard groups-for example, carcinogens, reproductive toxins, corrosives, flammables, ignitables, EPA Reportable Quantities, reactives, "highly toxics," and air toxics.

This model program was determined to be worthy of piloting and was piloted successfully at Brookhaven National Laboratory. Because of its broad capabilities, it is highly recommended for consideration and use by other DOE sites and facilities.

\section{Policies and Procedures}

PNL established a policy that all chemicals will be ordered through the CMS beginning January 1, 1993. The system is controlled by the Laboratory Safety Department. Copies of the policy have been distributed to all affected employees, and key staff members have been trained to use the CMS.

Included in the submittal were detailed implementation procedures and a full discussion of the key process performance requirements. With this information, a site or facility can rapidly determine and correct bottlenecks to implementation.

In 1990, PNL management recognized that the laboratory would have to centralize and standardize the information about the chemicals it used. Management followed through, committing many person-years, buying equipment, and sustaining funding at a level adequate to ensure that the program would succeed. The CMS took almost two-and-a-half years to bring from inception to full operation. The implementation cost an estimated $\$ 625,000$, of which $\$ 213,000$ will be recurring costs.

A group of 18 employees developed the key performance requirements over a 3month period. As the CMS software was developed, the modules were tested in one research organization and feedback was collected. For nearly a year, as the system was being introduced laboratorywide, employees were given further opportunities to say what they found to be its strengths and shortcomings. To ensure that this feedback would continue, the programmers furnished the software's interface with a screen in which users are encouraged to post their ideas for making the CMS more effective and easier to use. In addition, trainees are invited to rate the training program on a questionnaire they receive once they complete their training.

There are no regulatory requirements for training in a program like this one. However, the program requires training to be used effectively. The introductory training lasts 2 hours. Over time, an employee can become more efficient by following the manual chapter by chapter. How many days or weeks this requires will depend on

Training 
the individual's learning curve. Copies of the lesson plan and a detailed user's guide can be found in the model program package.

The PNL CMS is very useful for managing chemical hazards. Through the building inventory loading reports, CMS enables managers to prevent hazardous materials from accumulating. In addition, the system generates a daily exception report that informs management when excess quantities of chemicals have accumulated in an area.

In some DOE organizations, it may be necessary to establish two full-time program positions: a CMS manager and a technician to perform data entry and system development. Material resources for the CMS included a Sequent Symmetry multiprocessing computer running a POSIX-compliant version of Unix. The development tools included Oracle Relational Database Management System, Version 6.0; SQLForms, Version 3.0; C code embedded with SQL using Oracle's Pro*C precompiler, Unix C Shell and Perl scripts.

For a three-ring-bound, comprehensive description of this model program, call Ed Patigalia, OSHWPP Mariager, U.S. Department of Energy, EH-51, at (301) 903-3972.

For answers to specific questions about PNL's Chemical Management System, call Richard Johanson, Model Program Principal Contact, at (509) 376-1586.

To leam about Brookhaven National Laboratory's experience piloting the program, call Wendy Mosca at (516) 282-4935.

For additional information about this model program, call Joseph Sutey, U.S. Department of Energy-Richland Operations Office, at (509) 372-4005.
Hazard Abatement and Control

\section{Resources}

\section{Points of Contact}




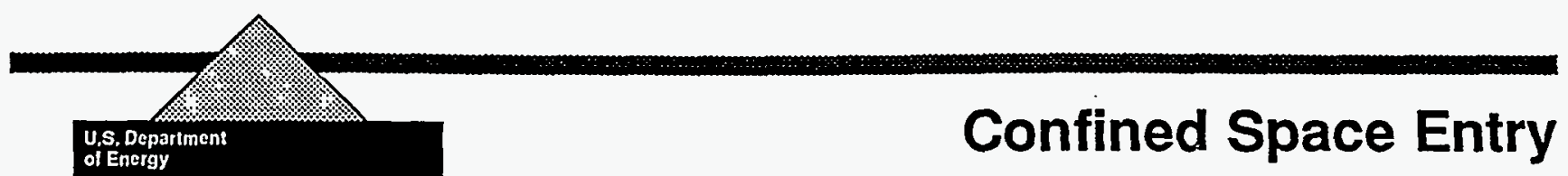

Martin Marietta Energy Systems, Inc. Oak Ridge K-25 Site Submitted December 1992

In April 1990, to unify its confined space training across sites, Martin Marietta Energy Systems, Inc. (MMES) convened a technical subcommittee on confined space entry. The meeting drew representatives from all five company sites: K-25 Site (Oak Ridge, TN), Oak Ridge Y-12 Plant, Oak Ridge National Laboratory, Paducah Gaseous Diffusion Plant, and Portsmouth Gaseous Diffusion Plant. After comparing programs, the representatives agreed that the most comprehensive offering was the Confined Space Entry Program (CSEP) developed at K-25. Accordingly, that program became the model for the cross-site MMES program.

Going beyond U.S. Occupational Safety and Health Administration (OSHA) minimum requirements established for a performance-based standard, the program ensures that the risk of entering, working in, and exiting a confined space is as low as reasonably achievable (ALARA). The program recognizes that preventing confined space casualties requires cooperation between entrants, attendants, supervisors, management, and health and safety professionals.

The Confined Space Data Base of Oak Ridge $\left(\mathrm{CONDOR}^{\circ}\right)$ was developed as a tool for storing and retrieving information associated with confined spaces. Confined space descriptive information is maintained in a master data table; air monitoring data are maintained in a separate system database. Novel features include the confined space evaluation checklist, hazard assessment data, and the capability of viewing digital photographs of selected confined spaces through a graphics file associated with each data record. The software allows health and safety professionals to track a large number of confined spaces onsite and enables users to quickly retrieve information on each confined space and access historical monitoring data as well.

This model program provides examples of engineering controls, surveillance methods or techniques, implementation plans, quality assurance plans, permits, construction contract addenda, and other support documentation necessary to create a confined space entry program that is fully functional. The program encompasses all workers who may have occasion to enter confined spaces, including subcontractors, service contractors (such as the telephone company), and incidental visitors.

\author{
Program \\ Summary
}


Noteworthy Practice
This program became one of four selected to be piloted. The pilot facility was West Valley Nuclear Services, Inc. The intentional pairing of a large facility with a relatively small, operationally dissimilar facility resulted in considerable cost savings and the elimination of duplicative work for the pilot facility. The pilot effort advanced into a mature program within a short time frame.

OSHA requires confined spaces to be classified as "permit required" or "nonpermit." The K-25 program goes beyond this requirement: all spaces require a permit. They are classified as high risk or low risk, based on the hazard's severity and likelihood.

In addition, all entrants, attendants, and rescuers must be physically and psychologically suited for the work and stresses imposed by confined spaces.

Procedures and operating instructions are set forth in eight guidance documents complemented by a QA plan that includes a process flow diagram, an organizational chart, a responsibility profile, a responsibility matrix, departmental procedures, and procurement and verification methods. Also provided are a list of records and controlled documents, examples of nonconforming items, a surveillance schedule, and a quality assessment form. A requirements table lists the regulations, standards, and orders that govern the $\mathrm{K}-25$ confined space entry program. Copies of all these documents can be found in the model program comprehensive description.

$\mathrm{K}-25$ Site management plays a significant role in directing overall policy setting. Through policy statements, surveillances, self-assessments, safety meetings, bulletins, and training courses, management has established the importance of the Confined Space Entry Program and the necessity for strict adherence to all confined space entry requirements.

As the model program was being developed, MMES employees participated at every step, drafting documents and providing the real-world experience necessary to ensure that the program would be practical and accepted. Today, employees and subcontractor personnel submit safety suggestions and participate in debriefings when subcontractor personnel are involved in confined space entry operations.

Each individual is given the authority to stop work if conditions appear unsafe.

Five training modules cover the functional tasks related to confined space entry. Personnel are trained as entrants and attendants; supervisors; atmospheric testing personnel; and emergency response personnel. All subgroups must complete a general training module. The training is comprehensive and meets all requirements of the OSHA 29 CFR 1910.146 and ANSI Z117.1 standards. Records are kept in a training management information system. 
Personnel are trained prior to being assigned to confined space duties or when their duties are changed to require confined space entry or work. If a worker fails to comply with procedures, retraining may be recommended. Supervisors and the Confined Space Program Coordinator help determine, at their discretion, whether individuals must be trained. Other options are available, including further education and discipline.

The ALARA philosophy is put into practice through the use of engineering controls, where feasible, supplemented by administrative controls and personal protective equipment (PPE). PPE is used only as a last resort, after engineering and administrative controls have been put in place.

Contractor and subcontractor personnel who perform confined space entries are debriefed following completion of work to determine whether any unanticipated hazards were encountered or created during the entry operations.

The K-25 Site used inhouse personnel to identify and classify more than 3,000 confined spaces. A subcontractor was used to assist in compiling the classification information into a database. The $\mathrm{CONDOR}^{\circ}$ database is programmed in Clipper 5.2 and is dBase ${ }^{T M}$ compatible. The database can be customized easily to meet a site's specific needs.

A site that is considering whether to adopt the $\mathrm{K}-25$ Site Confined Space Entry Program should budget for health and safety personnel and for material resources such as full-body harnesses, mechanical aids for entry/rescue, sampling instrumentation, and training simulators.

For a three-ring-bound, comprehensive description of this model program, call Ed Patigalia, OSHWPP Program Manager, U.S. Department of Energy, EH-51, at (301) 903-3972. The original, 1992 binder was updated in January 1994 to incorporate the experience of the pilot program.

For answers to specific questions about Oak Ridge $\mathrm{K}-25$ Site's Confined Space Entry Program, call Angela D. Arms or Ted C. Helms, Model Program Principal Contacts, at (615) 574-8847 or (615) 574-8622.

To leam about West Valley Nuclear Services' experience piloting the program, call Frank Kempisty at (716) 942-4856.

For additional information about this model program, call Tom $\mathrm{H}$. Youngblood, U.S. Department of Energy-K-25 Site Office, at (615) 576-2807.

\section{Hazard Abatement and Control}

\section{Resources}

\section{Points of Contact}




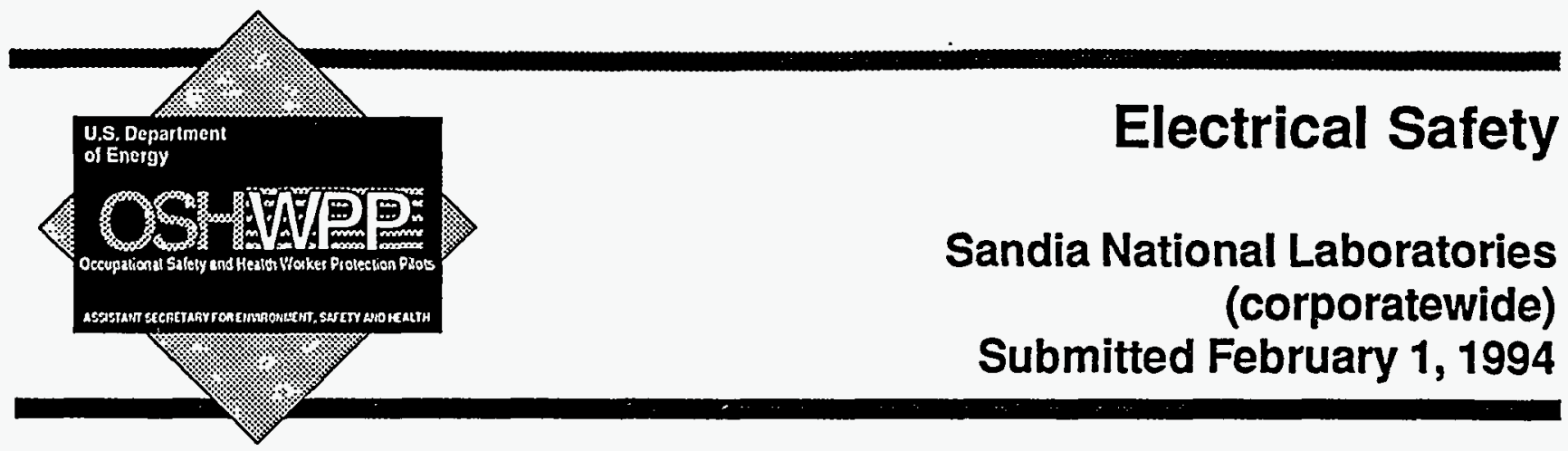

The Sandia National Laboratories (SNL) Electrical Safety Program was developed to provide an electrically safe workplace for all employees and onsite contractors of SNL by minimizing electrical risks.

By the late 1980's, as high-energy research and development had grown increasingly complex, SNL workers faced new electrical hazards. Rapid facility growth, meanwhile, had placed new demands on electrical maintenance workers; more than ever, they had to be ready for electrical hazards at any time, vigilantly adhering to safe operating procedures. At the same time, electrical regulations had proliferated. The time had come for a comprehensive program that would govern electrical safety corporatewide. This program would provide the plan for the implementation of all electrical safety standards of the U.S. Occupational Safety and Health Administration (OSHA) and the U.S. Department of Energy (DOE).

Any electrical safety program strives to prevent workers from coming into contact with live or energized regions of wiring or equipment. SNL approached the task with an unusual core conviction: Electrical safety need not be complicated. Underscoring this conviction is a simple three-pronged strategy: (1) raise the awareness of individuals who might be exposed to the risk of shock, (2) train all who are at risk in electrical safety, and (3) require safe electrical work practices.

Under the SNL program, electrical safety is the concem of all SNL employees, especially electricians, scientists, engineers, and technicians. Responsibilities, policies, and procedures are spelled out in a Corporate Electrical Safety Program document. Though worded generically, this document can be used as a template to develop site- or project-specific programs. Indeed, the program has been piloted by AlliedSignal at the Kansas City, Missouri, site.

The opening chapter of the SNL ES\&H Manual spells out the responsibilities of the Electrical Safety Committee. Among these responsibilities, the committee ensures that SNL is complying with the National Electrical Code, the National Electrical Safety code, and OSHA electrical regulations.

\section{Program \\ Summary}

\section{Policies and Procedures}




\section{Management Commitment}

\author{
Employee \\ Involvement
}

\section{Training}

\section{Hazard \\ Abatement and Control}

The Safety Department has dedicated four full-time employees to improving electrical safety. In memos to employees, upper management has affirmed its support for the program's participants. In the wake of a safety inspection, department managers must sign the forms bearing the findings and the corrective actions that must be taken to remedy electrical hazards. Managers must also ensure that their employees have completed any required reading conceming electrical safety.

As the SNL's electrical safety program was being developed, employees were involved. The program document, for example, was evaluated by employees; their comments, in tum, were reviewed and resolved. Serving on the SNL Electrical Safety Committee are employees from every division and a representative from their union (the Metal Trades Council). Before a new standard operating procedure (SOP) can be implemented for electrical work, affected employees review it and validate it. Once validated, the SOP becomes a part of their required reading.

All training courses meet OSHA and DOE requirements for content and length. All employees receive the required training before being exposed to hazards. Lesson plans are reviewed for technical content and compliance with regulatory requirements.

Certified Electrical Inspectors evaluate how effectively electrical safety procedures are implemented during construction, operations, and experimenter activities. Once a hazard is identified, supervisors must respond promptly to eliminate it or provide interim protection. Each department manager must develop and implement an action plan for documenting and correcting electrical deficiencies.

Finally, the program requires the use of specific types of personal protective equipment (PPE). The procedures describe the types of PPE required and identify choices by make and model.

At SNL—a high-technology laboratory-sufficient numbers of trained, qualified electrical safety personnel are available to support the program as part of their routine duties. Less than 10 percent of program development and implementation activities were performed by outside providers. While other sites may have fewer electrical safety resources, the SNL Electrical Safety Program manager has authorized the resources necessary to provide interested DOE sites with details of SNL's program. 
For a three-ring-bound, comprehensive description of this model program, call Ed Patigalia, OSHWPP Program Manager, U.S. Department of Energy, EH-51, at (301) 903-3972.

For answers to specific questions about SNL's Electrical Safety Program, call Hugh Bundy, Model Program Principal Contact, at (505) 845-9806.

To leam about AlliedSignal's experience piloting this program, call Don Fitzpatrick at (816) 997-5899.

For additional information about this model program, call Michelle Chavez, U.S. Department of Energy-Kirtland Area Office, at (505) 845-4419. 


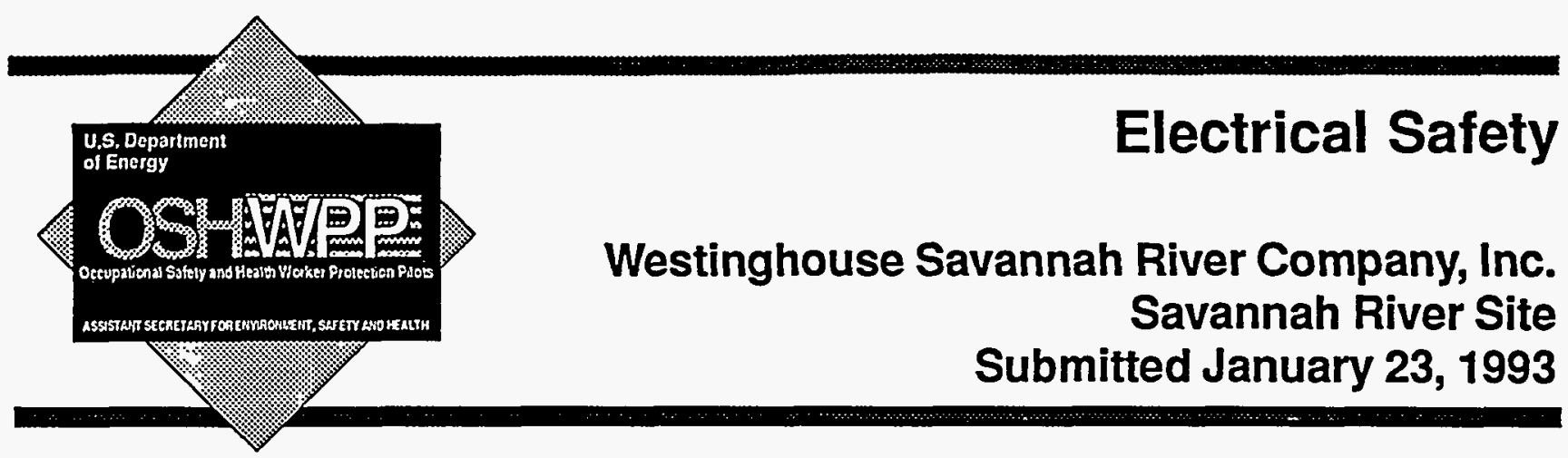

The Savannah River Site is so vast that by the early 1990's some 23 procedures, and several electrical safety policies and training programs, had independently taken root at various locales. To unify these practices while lightening the administrative burden needed to maintain them, in 1992 Westinghouse Savannah River Company (WSRC) began to consolidate these efforts. With a unified set of guidelines for controlling electrical power, employees and contractors could be reassigned from area to area without having to learn a new set of rules each time.

Two years earlier, a Senior Electrical Review Board (SERB) had been formed to encourage electrical workers throughout the site to share information about industrial electrical power and control. SERB members provide technical support to the Works Engineering Steering Committee. They also help improve existing electrical standards.

Each year, the Industrial Safety Section, through its Industrial Safety Reviews and Audits Group, conducts an OSHA-like inspection to identify problem areas in electrical safety. To augment this effort, in 1994 WSRC developed an Occupational Safety and Health (OSH) Area Coordinator Program. These Area Coordinators serve as "local experts," providing management with day-to-day insights into the electrical safety concerns unique to their areas.

Submitted in response to the initial call for programs, WSRC's Electrical Safety Program was judged exemplary. Other sites and facilities are urged to adopt it in whole or in large part.

Central to the program are three sitewide procedures:

1. "Basic Electrical Safety Awareness" defines responsibilities so that individuals will recognize electrical hazards before they or their co-workers are injured or killed. This procedure is binding on all employees of WSRC and Bechtel Savannah River, Inc., as well as on subcontractors exposed to electrical hazards.

2. "Safe Practices Near Electrical Conductors" provides the minimum requirements for safely working on or near electrical conductors. It covers training
Program Summary

\section{Policies and Procedures}




\section{Management Commitment}

\author{
Employee \\ Involvement
}

qualifications, test equipment, tools, protective equipment, approval levels, and attendants required for various tasks.

3. "De-Energize, Lock, Tag, Test, and Ground Electrical Circuits and Substations" specifies the test and safety equipment to be used.

All three procedures require employees to be trained and retrained. The latter two specify levels of proficiency for performing the work either supervised or unsupervised. Each procedure sets forth steps for disciplining and spells out responsibilities.

While these three procedures form the core, the model program also provides safety procedures covering batteries; fuses; removing power circuits from service; using a "Wiggie" test station; wearing jewelry or metal accessories; performing nonelectrical work near overhead lines; and controlling hazardous energy.

Much time and many staff-hours were authorized to put in place the internal inspections, establish the SERB, and consolidate the electrical safety efforts under a single program. In addition to committing significant resources, management requires that Design Engineering formally review every design of a new piece of equipment from the standpoint of electrical safety. Finally, all supervisors receive a safety newsletter describing incidents involving electrical safety.

During the trial program, everyone involved was encouraged to offer suggestions. As the consolidation evolved, employees of many levels and skills offered their say. As the procedures were reviewed, key individuals were asked to comment.

In a related electrical safety thrust, the SERB includes experienced workers and asks them to concur on its decisions.

During general employee training, all employees are made aware of the general policies covering electrical safety. They are required to read the procedure, "Basic Electrical Safety Awareness." Certain nonelectrical employees may incidentally be exposed to energized electrical equipment. All such employees must be suitably trained and given job-specific safety instructions before starting any new task.

An extensive training program covers all employees who work directly with potentially energized electrical systems. For this program, all formal training must meet the requirements of the site's three Training Accreditation Program (TAP) Manuals. For example, lesson plans are developed by training experts but reviewed by subject-matter experts. Once in place, lessons are revised to incorporate suggestions offered by the students. Training records are used to determine whether an employee being considered for a specific job is qualified. All participants in the training are evaluated by written exams, hands-on training, or laboratory work-whichever method best suits the subject matter. Annual refresher training is provided. Copies of some lesson plans can be found in the model program submittal. 
Because electricity behaves in ways that the average layperson cannot reliably predict, if a piece of electrical equipment needs a part the replacement must be identical (a "replacement in kind"); all exceptions must be authorized by a design engineer and approved by the SERB. When planning how to abate potential hazards, engineers rely on engineering controls together with personal protective equipment. The abatement procedures are spelled out in the procedures.

The program calls for a cadre of electrical design engineers, electrical safety specialists, and trainers who understand electrical systems and the cautious working practices they require. Because several electrical safety organizations were being consolidated, a number of professionals were on hand to implement the program. Additional staff were needed to prepare the extensive training program. A site seeking to implement a similar program may need to redefine certain roles.

No unique or specialized material supplies are necessary.

For a three-ring-bound, comprehensive description of this model program, call Ed Patigalia, OSHWPP Program Manager, U.S. Department of Energy, EH-51, at (301) 903-3972.

For answers to specific questions about WSRC's Electrical Safety Program, call Lisa Skinner, Model Program Principal Contact, at (803) 644-5653, or Joel T. Andrews, WSRC SERB Chairperson, at (803) 725-5839.

For additional information about this model program, call Roger D. Rollins, U.S. Department of Energy—Savannah River Operations Office, at (803) 725-3956.
Hazard Abatement and Control

\section{Resources}

\section{Points of Contact}




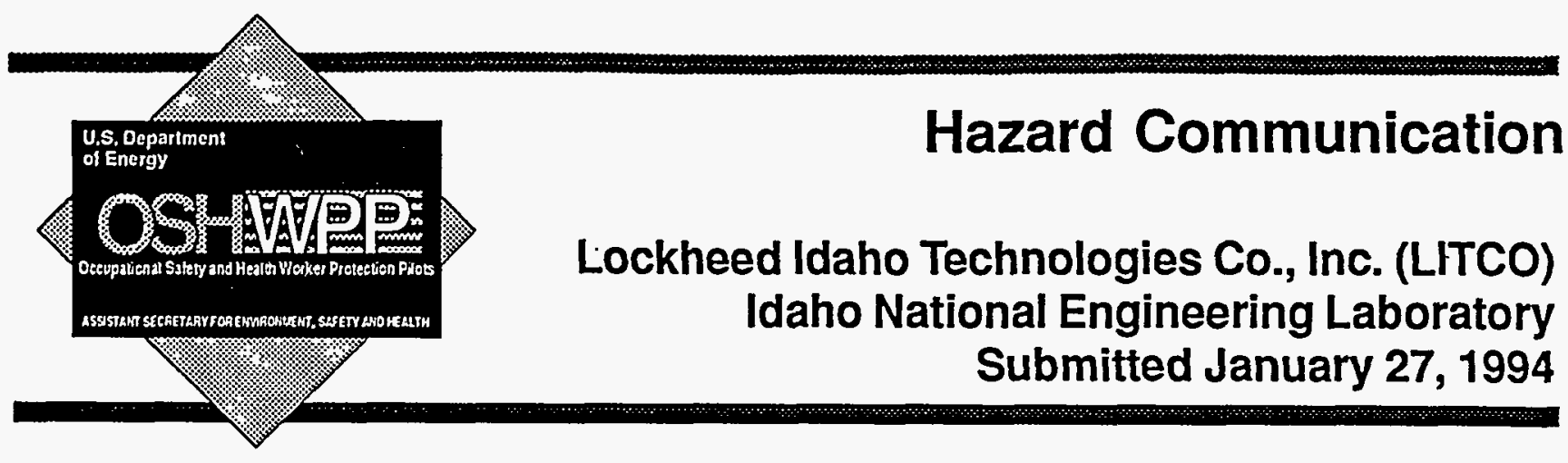

The goal of any hazard communication (HazCom) program is to ensure that employees understand the materials they are using and know how to protect themselves from the dangers of use and exposure. In 1990, a group of industrial hygienists at Program
Summary EG\&G Idaho (now Lockheed Idaho Technologies Company, or LITCO) set about to develop a program to meet this goal, protecting all EG\&G Idaho employees, contractors, and visitors. With input from many others, they developed an exemplary program. One of the OSHWPP model programs, it was piloted at Argonne National Laboratory-East.

This program consists of five components: a procedure, a database, a procurement control system, a labeling system, and training. Before a chemical can be procured or used onsite, it must be reviewed and approved by an industrial hygienist. In this way, LITCO minimizes the presence of carcinogens and limits the volume of chemicals that must be treated as hazardous waste.

The program database provides the "list of chemicals" required by regulation (29 CFR 1910.1200, "Hazard Communication") and an inventory of physical and biological hazards required by DOE Order 5480.10 ("Contractor Industrial Hygiene Program").

The containers of chemicals are labeled with the original manufacturer's label. If this label is inadequate or the chemical is not in the original container, a supplementary label is affixed to identify the hazard, spell out protective measures, and provide emergency response information. New chemicals may not come onsite or be used until a Material Safety Data Sheet (MSDS) is available. The database is supplemented with hard copies of MSDS's, which are available in each work area.

The program applies a company policy that makes unit managers responsible-and accountable - for safety and health issues. These managers are responsible for ensuring that MSDS's in their area are current, that employees have been trained, that waste minimization practices are followed, and that reporting requirements are met. All company employees receive general HazCom training as new hires; many also receive an annual refresher. 


\section{Policies and Procedures}

\section{Management Commitment}

Employee Involvement
The overall safety program approach at LITCO is based on five principles:

- line management ownership,

- line management self-assessment,

- planned approach,

- cognizant professionals, and

- independent oversight.

By company policy, safety is everyone's responsibility. Unit managers are accountable for ensuring the safety of all personnel, facilities, and operations under their control.

Chemicals are inventoried in a companywide database. Unit and laboratory managers are responsible for updating the database and maintaining organized hazard communication directories to ensure that employees have ready access to the information. They also must ensure that, within their area, the labels on all containers of hazardous materials are legible and accurate, and that these labels are cleaned and updated as necessary. Finally, these managers must ensure that job-specific training is provided to all employees who report to them, including contractors, transient employees, and out-plant employees.

Supporting the managers are the Environment, Safety, and Quality Department, a hazard communication working group, a hazard communication coordinator, and departmental hazard communication representatives.

The model program comprehenisve description includes full copies of the procedures, describes the inventory database, and explains the MSDS support provided by the Chemical Services Unit.

Management has shown its commitment by hiring a full-time HazCom coordinator.

Selected groups of technically cognizant employees helped the four founding industrial hygienists develop and implement the program. Now that the program is in place, employees note deficiencies and, through their departmental hazard communications representatives, suggest ways the procedures can be improved.

During orientation, all new hires receive 3 to 4 hours of general HazCom training. Once at work, they receive job-specific training; the content and length depend on their risk category, which is derived from their expected exposure. There are four risk categories; employees in the higher two receive annual refresher training.

Certain employees and managers are trained to use the inventory database. The HazCom representatives receive training to upgrade their qualifications. 
This program relies chiefly on administrative controls: personnel are taught to fully recognize hazards before becoming exposed. Under some circumstances, certain personnel must wear personal protective equipment and managers must implement engineering controls. While chemical hazards will never be completely eliminated, LITCO's industrial hygienists hope that by screening chemicals before ordering them, they will eliminate or limit potential exposure.

The program requires that line managers assume additional responsibilities. However, they are assisted by the Environment, Safety, and Quality Department, which provides major technical coordination and oversight. Within the Chemical Services Unit, three full-time equivalents are dedicated to maintaining the MSDS's.

For a three-ring-bound, comprehensive description of this model program, call Ed Patigalia, OSHWPP Program Manager, U.S. Department of Energy, EH-51, at (301) 903-3972.

For answers to specific questions about LITCO's Hazard Communication Program, call Mr. Kiely Parker, Model Program Principal Contact, at (208) 526-2522.

To learn about Argonne National Laboratory's experience piloting this model program, call Mary Grace at (708) 252-3306.

For additional information about this model program, call Cheryl Floreen $(\mathrm{CIH})$, U.S. Department of Energy-Idaho Operations Office, at (208) 526-0874.

\section{Hazard Abatement and Control}

Resources 


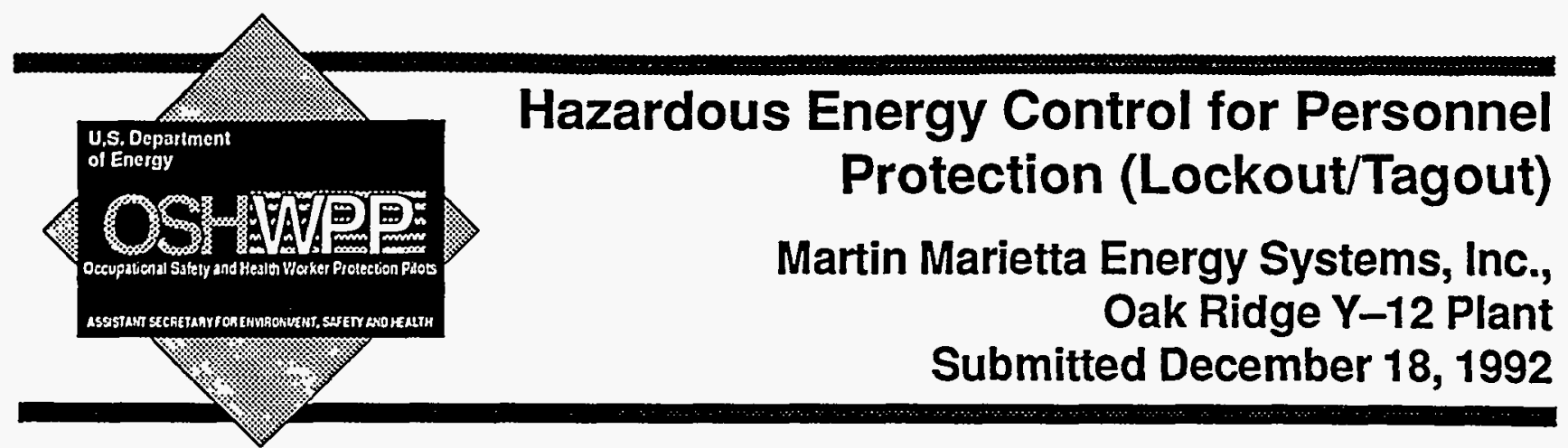

The Y-12 Plant spent about 1 year developing and refining the procedures, forms, tags, hardware, and training that support the site's Lockout/Tagout (LO/TO) program. The program fully complies with LO/TO-related aspects of OSHA 29 CFR 1910.147 ("Sources of Standards") and 29 CFR 1910.333 ("Selection and Use of Work Practices"), as well as DOE Order 5480.4 ("Environmental Protection, Safety and Health Protection Standards").

Martin Marietta Energy Systems, Inc. (MMES) developed this program to control energy sources that could injure workers should stored energy unexpectedly energize or release when a system or piece of equipment was being installed, built, repaired, adjusted, inspected, tested, or maintained. Electrical energy isolation at potentials above 600 volts is covered through the Electrical Permit System.

Note: Since this program was submitted, it has undergone major revisions. The summary presented here describes an earlier version of the program. However, MMES's program contact will be more than happy to answer questions from interested sites.

The model program submittal contains copies of the MMES corporate LO/TO and Employee Discipline procedures as well as the Y-12 Plant Energy Isolation and Control (Lockout/Tagout) and Positive Discipline procedures. Also included are the lesson plan for the 4-hour training course, the support documents, and the end-ofcourse examination.

To help other sites implement this model program, MMES has provided a flowchart that identifies the milestones reached and problem areas encountered at Y-12.

The LO/TO program considers all forms of energy, both latent and residual, not only electrical ( 600 volts and below), but also hydraulic, pneumatic, mechanical, chemical, and radioactive. It has two levels: (1) a "permit required" level, where the lockout/tagout will affect personnel other than an individual, and (2) a "permit not required" level. There are also provisions for temporarily suspending a permit to test a function while a system or piece of equipment is being maintained or repaired.

Program Summary
Noteworthy

Practice 


\section{Policies and Procedures}

Personnel who have been trained in LO/TO prior to the annual retraining may take a comprehensive proficiency test. If they satisfactorily complete this test, they do not have to take the 4-hour training. They are asked to read and sign a sheet that lists deficiencies found during audits and surveillance of LO/TO activities during the preceding year. The signed document and the test results are put in the training folder and the personal training record is updated.

The Y-12 Plant policy and expectation of worker protection is reflected in the scope and purpose of the procedures that drive the program. The procedures apply to all MMES-managed facilities on the Y-12 Plant site.

Health and Safety Procedure Y70-527, "Energy Isolation and Control (Lockout/ Tagout)," does not apply to electrical circuits and live parts that operate at less than 50 volts to ground, provided there will be no increased exposure to either electrical bums or explosion that might arise from an electrical arc.

Plantwide implementation of the LO/TO process is invoked after extensive training of all personnel who will authorize the use of, apply for, work under the protection of, or release locks and tags. All other plant personnel are briefly trained in the fundamentals of the procedure; the emphasis is on the need to recognize and respect locks and tags applied for personnel protection.

The LO/TO permit is initiated by the issuing authority, an individual who is designated or approved by the division manager, trained, and has jurisdiction over the equipment or systems to be locked out. This person also controls a lock box, verifies conditions, obtains the appropriate signatures, and in other ways controls and coordinates all activity under the permit.

Devices or equipment that cannot be locked out are labeled with a tag reading "Danger-Do Not Operate"; a tear-off tab from the tag is placed in the lock box. Service personnel apply individual locks to the lock box.

Management assigns personnel and equipment resources to the continuing development and implementation of the program. A special readiness review is conducted by key division managers prior to implementation to ensure that the plant is ready and able to implement all aspects of this procedure. Management continues support by applying positive discipline for noncompliance and prompt, comprehensive actions to correct deficiencies or other findings of noncompliance.

Management audits the LO/TO process through a standardized inspection form, called a Surveillance Guide. Audits are summarized in a report to the responsible parties and periodically reviewed by management. 
The initial procedure was developed by a plant-level committee, including union representatives. Selected groups of employees provide direct input on their concerns. The pilot training program also solicits employee comments by the review process.

Through interviews held during the first quarter of implementation, feedback is obtained from employees who will be directly affected. This information can be used to clarify general issues and to revise the procedure and the training. Employee input is also solicited through injury and incident investigations and the safety suggestion process.

This model program includes two levels of training. First, employees directly implementing the procedure are trained for 4 hours. They are also subject to annual retraining of 4 hours, or they may test out and receive only an update on the recent incidents and revisions to the process.

The second, higher training level addresses those who have a need for awareness of the program. This level instills respect for placing locks and tags and the consequences of ignoring them. It is repeated every 2 years. This training is a segment in the general employee training for new hires or unescorted non-MMES workers.

Between training sessions, those who are already proficient in the process receive handouts as procedures change.

The program hinges on the proper use of engineering controls. If a system or item of equipment is not directly controllable through the use of locks, the documentation and accountability for tagging requirements increase. Anytime an engineering design standard is changed, the new version must require all new and modified installations to come equipped with a means of lockable energy isolation. The system/ equipment drawings must identify energy-isolating devices.

The use of personal protective equipment is minimized during work under the protection of locks, but it is specified during the application of the locks and under tagprotected systems, as appropriate.

The use of existing personnel with some changes in responsibility is key to the success of the program. The training sessions have a significant impact on the normal work schedules. For example, individuals within each area or department must be designated as issuing authorities, and a trainer must be authorized and committed to deliver the levels of training. Participants in the training must have 4 hours available for the initial and annual retraining needs.

Material supplies include large quantities of locks, tags, nylon tag attachments, lock boxes, logbooks, permits, and procedures.

\section{Employee Involvement}

\section{Training}

\section{Hazard Abatement and Control}

\section{Resources}


Points of Contact
For a three-ring-bound, comprehensive description of this model program, call Ed Patigalia, OSHWPP Program Manager, U.S. Department of Energy, EH-51, at (301) 903-3972.

For answers to specific questions about Hazardous Energy Control for Personnel Protection, call Mary A. Groh, MMES, Y-12 Industrial Safety Department and Model Program Principal Contact, at (615) 576-2367.

For additional information about this model program, call R.J. Spence, U.S. Department of Energy-Oak Ridge Operations Office, at (615) 576-0755. 


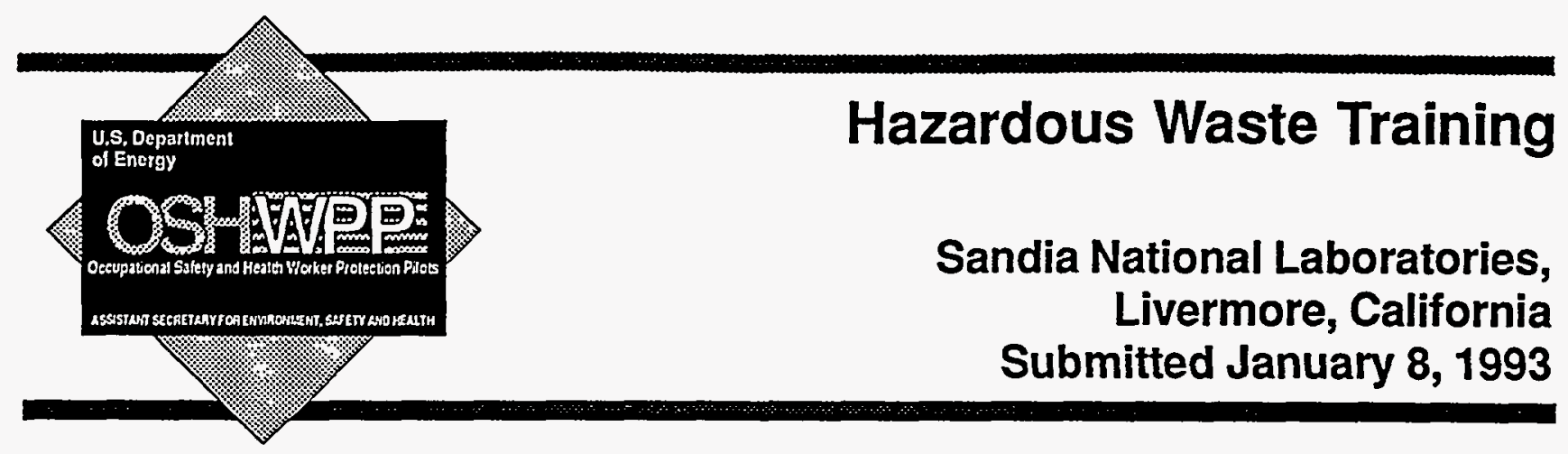

At Sandia National Laboratories-Livermore, CA (SNL/CA), everyone who works with hazardous, radioactive, or mixed waste is familiarized with and trained to perform all facets of his or her job within the context of occupational safety. Broad in scope, the program is entitled "The SNL/California Environmental Protection Department Training Program and Job Descriptions for the Management of Hazardous, Radioactive and Mixed Wastes." Medical wastes are covered in a corollary program. After completing the program, an employee knows how to store, handle, test, dispose of, compact, and manage records for a variety of wastes. A key part of the program is to spell out who is responsible at each step in the material's life cycle-for example, who is to complete a checklist, who is to maintain a training database, and who is to submit records for filing.

Technicians leam how to minimize the volume of waste they generate. They also learn how to clean all equipment and containers after use in a manner that is both safe and environmentally sound.

The training program is a core part of a hazardous waste management program that in 1991 was rated Exemplary by the then DP-67 (Defense Programs' Office of Inspections). All procedures and job descriptions are clearly written, reviewed annually, and updated when necessary. They can be easily incorporated into training classes or adapted to other sites. While the training program content is tailored to the Livermore site, the program, with suitable "localizing," would make an outstanding contribution to any DOE site that generates hazardous wastes.

While every site counts hazardous waste safety among its policies, SNL/CA has gone a step further, building the policy into the job description of each member of the Environmental Protection Department's Waste Management Group. Accordingly, each such employee must be thoroughly trained in the regulatory requirements of waste management. By requiring and providing this training, SNL/CA ensures that everyone involved with waste management is highly qualified.

In addition to teaching basic operating procedures, the program covers waste packaging and labeling, testing of unknown substances, waste compatibility, storage, and shipping.

\section{Program \\ Summary}

\section{Policies and Procedures}




\section{Management Commitment}

\section{Employee Involvement}

\section{Training}

Resources
SNL/CA's commitment to the program is demonstrated through the extensive training provided on company time to all individuals responsible for handling hazardous wastes generated at the facility, both employees and contractors. All who wish to take further training are permitted and encouraged to do so. Moreover, everyone involved in hazardous and radioactive waste management receives a copy of the training program and is advised quarterly about upcoming training requirements.

Before completing the job descriptions, the training program developers conferred with the affected employees, who validated the procedures. Employees are encouraged to point out ways the hazardous waste procedures can be improved. During class, employees are encouraged to speak up to illustrate or clarify the instructor's points.

Participants learn how to select, don, and remove personal protective equipment; select and implement engineering controls; prepare and follow emergency response plans; enter confined spaces; practice radiation and fire safety; monitor equipment; and ensure that deficient equipment meets lockout/tagout requirements.

The hazardous waste management program was expressly designed to meet the training requirements of Federal regulations and laws, DOE Orders, and other mandates. While hazardous waste theory is included, the emphasis is on performance. No one is exposed to a potentially hazardous work environment without direct supervision until completing the program. However, at the end of the course students are assessed by quizzes or exercises to ensure that they adequately understand how to apply what they have leamed.

Training records are reviewed quarterly to verify who has participated. The program explains how much expertise is required to carry out specific assignments. As new training courses and familiarization courses are developed, personnel are trained accordingly during refresher training. In December 1994, SNL/CA was developing a matrix that would establish what level of training is required (for example, reading, on-the-job training, or classes) for each employee and each site-specific procedure.

By design, this hazardous waste program is taught and managed by existing staff. Other sites should likewise be able to adopt it without hiring new trainers or administrators. However, some portions of the required courses are highly specialized and may need to be taught off-site at special facilities or on-site by a visiting expert. 
For a three-ring-bound, comprehensive description of this model program, call Ed Patigalia, OSHWPP Program Manager, U.S. Department of Energy, EH-51, at (301) 903-3972.

Points of Contact

For answers to specific questions about SNL/CA's hazardous waste training programs, call Gwyn Faulkner, Model Program Principal Contact, at (510) 294-2604, Monday through Wednesday.

For additional information about this model program, call Kathleen A. Carlson, U.S. Department of Energy-Kirtland Area Office, at (505) 845-4094. 


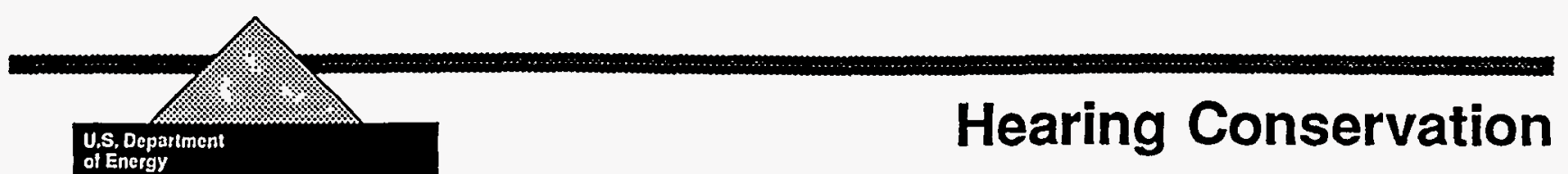

\section{Martin Marietta Energy Systems, Inc. Oak Ridge Y-12 Plant Submitted December 18, 1992}

Y-12 Plant's Hearing Conservation Program (HCP) is a system for assessing, preventing, and controlling potential changes in personal hearing thresholds (volume or frequency) from occupational exposure to noise. The program emphasizes the use of engineering controls, together with personal-area or general-area noise surveys to be performed by the Industrial Hygiene Department. By providing survey schemes and detailed descriptions of personnel responsibilities, the program provides several checkpoints for keeping uncontrolled hazards out of the workplace. These elements, together with the complete text of the personnel training program, can be found in the model program comprehensive description.

Because many areas in a facility contain potential noise hazards, the HCP is designed to meet the requirements of 29 CFR 1910.95 ("Occupational Noise Exposure"), the two applicable DOE Orders (5480.4_ "Environmental Protection Safety and Health Protection Standards" and 5480.10 - "Contractor Industrial Hygiene Program"), and the MMES Occupational Noise Exposure and Hearing Conservation (ONEHC) Standard (ESS-IH-121).

The policy statement is embodied in the Y-12 Plant Health and Safety Procedure 70-203, "Hearing Conservation Program." Based on the four aforementioned documents, it is found in all bookracks that bear the plant procedures manual. The procedure applies to all personnel within the plant who are exposed to noise levels greater than or equal to an 8-hour Time Weighted Average (TWA) of 85 decibels on the A-weighted scale (dBA).

Those employees who have difficulty with the HCP become subject to Administrative Procedure 10-021, "Positive Discipline." That program enjoins managers to recognize good performance while correcting performance problems through coaching and cultivating a commitment to high work standards and safe work practices. Included in positive discipline are steps for encouraging an employee to correct errors before they become problems. Copies of the site discipline procedures are provided in the model program.

\section{Program Summary}

\section{Policies and Procedures}




\section{Management} Commitment
Because of the far-reaching implications in terms of quality and the number of employees potentially exposed to high noise levels at the $\mathrm{Y}-12$ Plant, the Hearing Conservation Program also has a Quality Assurance Plan. The QA Plan uses a matrix to identify which of the 18 elements of QA apply to the Hearing Conservation Program. This plan ensures that employee exposures to noise are as low as reasonably achievable (ALARA) provided that current engineering technology and effective program management are conscientiously applied.

The program identifies responsibilities by management title and division. Each manager signs a written commitment to the program. They show their commitment by conducting workplace inspections and formally performing self-assessments; by authorizing the requisite engineering changes to ensure that corrective actions are taken promptly; and by applying the positive discipline program.

Employees are enlisted to serve on committees and teams. Employees also chair or co-chair plant committee efforts, participate in employee reviews, comment on health and safety procedure documents, and participate in health and safety audits, surveillances, and inspections.

Employee feedback on programs is obtained through their comprehensive participation in health and safety training activities. Moreover, employees voice their concems and suggestions through the safety suggestion program. Finally, they identify potential program weaknesses when filling out their portion of accident and incident reports.

The training specified in ONEHC and incorporated into the HCP meets all regulatory guidelines. The amount of training employees and supervisors receive depends on regulatory requirements, job assignments, and the amount of noise to which they may be exposed. All employees covered by this program receive 1 hour of training on hearing conservation and protection and an annual refresher as long as they remain program participants.

A copy of the lesson plan can be found in the model program comprehensive description. Program elements are included in job-specific training through the use of supervisor-employee training sessions, safety meetings, and craft training modules. In the support staff, the Audiometric Test Administrator should be certified; this certification will require periodic refresher training.

All potential noise hazards are first identified by supervisors; they, in turn, contact the Industrial Hygiene Department. After characterizing the hazard, an industrial hygienist determines what interim personal protective measures are needed or begins taking steps to attenuate the noise source with engineering controls. The details of this process are found in the program's health and safety procedure. 
The program was developed by the highly trained and qualified personnel on the $\mathrm{Y}-12$ Plant staff. Sites that are considering adopting this model program may find that they can meet the needs of the program by using present staff in redefined or ancillary tasks. Two positions, however, will have to be filled by individuals working the better part of their time: Hearing Conservation Program Coordinator and Audiometric Test Administrator.

In addition to these personnel, certain material resources will be required: audiometric testing facilities and calibration equipment; noise survey instruments and calibration equipment; and adequate quantities and types of hearing protectors for the employees. (The exact mix will depend on tasks and type of potential hazard exposure.)

For a three-ring-bound, comprehensive description of this model program, call Ed Patigalia, OSHWPP Program Manager, U.S. Department of Energy, EH-51, at (301) 903-3972.

For answers to specific questions about Martin Marietta's Hearing Conservation Program, call Scott Hollenbeck, Model Program Principal Contact-Y-Y12 Industrial Hygiene Department, at (615) 574-9547.

For additional information about this model program, call Kenneth Leifheit, U.S. Department of Energy—Oak Ridge Operations Office, at (615) 576-0835.

\section{Resources}

\section{Points of Contact}




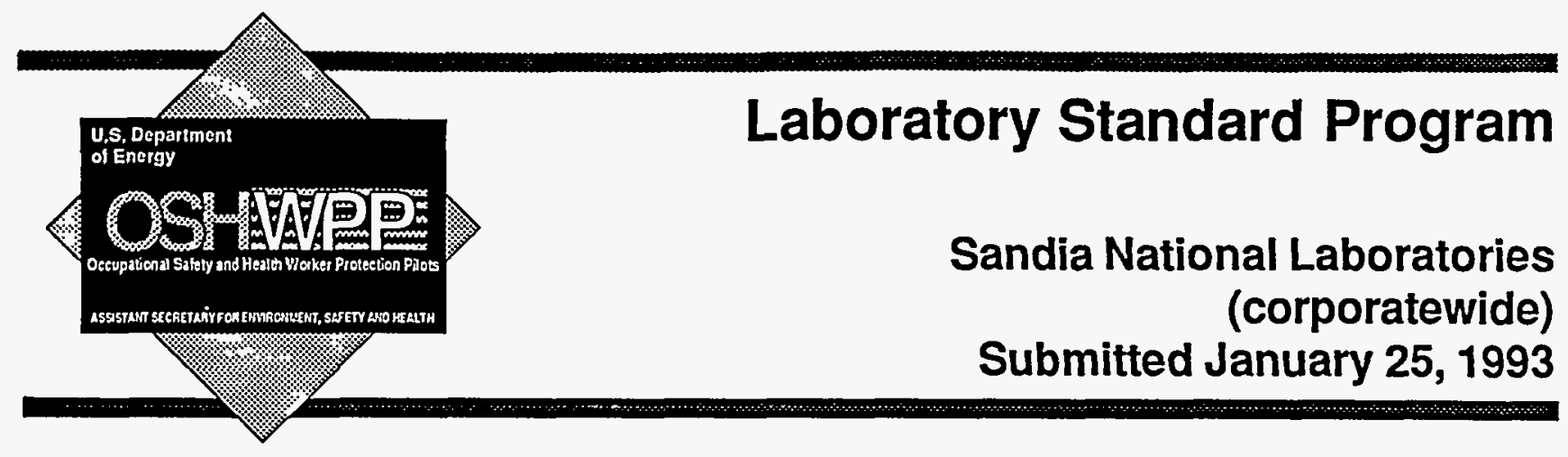

The Laboratory Standard Program emerged in 1990 at Sandia National Laboratories (SNL) in Albuquerque, NM. A team effort between Operations and the Industrial Hygiene/Toxicology Department, the program has earned the commitment and "ownership" of laboratory managers and employees.

At its most basic level, the program ensures chemical safety in laboratories by imposing a carefully planned hierarchy of documentation. Uniform corporatewide compliance guidelines are provided, in tum, by the Corporate Chemical Hygiene Plan, the Environment, Safety, and Health Standard Operating Procedure (SOP), and the Laboratory Standard Program operating procedure itself. This hierarchy of requirements provides uniform guidelines to the laboratories. It further provides safety and health procedural guidance specifically tailored to each laboratory's operations. Laboratories then have what amounts to their own customized industrial plans.

The Corporate Chemical Hygiene Plan is implemented and managed by a Corporate Chemical Hygiene Officer (CCHO), who is aided by some 48 deputies and laboratory operations staff. The deputies evaluate the plan annually. As the link between the CCHO and the SNL departments, they work with the CCHO and laboratory managers to correct weaknesses in the procedure.

This program meets the rigorous standards of the Department of Energy's Voluntary Protection Program. Its adoption or adaptation is recommended to all sites and facilities at which there are workplaces that must comply with the U.S. Occupational Safety and Health Administration (OSHA) standard.

In keeping with OSHA guidelines, a worksheet is used to determine whether a workplace is a "laboratory." If so, employee exposure to all chemicals must follow the principle of "as low as reasonably achievable" (ALARA). In addition to following ALARA, the lab must comply with all the provisions of the Corporate Chemical Hygiene Plan. All chemical work areas are governed by either the Laboratory Standard Program or the Chemical Hazard Communication Program.

\section{Program \\ Summary}

\section{Policies and Procedures}


For each directorate or department, the line organization director or department manager designates a deputy chemical hygiene officer. Implementing the Corporate Chemical Hygiene Plan falls largely on the shoulders of line supervisors. They ensure that SOP's are in place to protect employees from chemical health hazards. They also maintain an inventory of chemicals and a file of Material Safety Data Sheets (MSDS's) and resolve concerns about hazardous substances.

Individual workers are responsible for following the SOP's, understanding the properties of hazardous substances, practicing good personal hygiene, reporting incidents, and properly disposing of waste and excess chemicals.

The SNL/New Mexico Industrial Hygiene/Toxicology Department and SNL/Califomia Health Protection Department coordinate the activities under the Corporate Chemical Hygiene Plan. The two departments maintain records of workplace and air monitoring and set criteria for implementing controls. To facilitate oversight, the two departments maintain a centralized chemical inventory and MSDS information system. All chemical purchases and acquisitions are reviewed and logged into this system.

Management Commitment

\author{
Employee \\ Involvement
}

To ensure that the program manager's role meets OSHA's definition of a CCHO, management has assigned overall program responsibility to the manager of the Industrial Hygiene/Toxicology Department. Management's ongoing commitment is evidenced by the 48 deputy managers, who conscientiously inspect the laboratories and share their findings in an annual report.

Employees at several levels helped ensure that the program would meet the realworld needs of laboratory chemical safety. In addition to participating in incident reports and investigations, employees are asked to share their concerns on an Environment, Safety, and Health questionnaire and raise health and safety considerations regarding new activities or operations.

Employees are trained to understand the same kinds of chemical hazards covered by OSHA's Hazard Communication Standard (29 CFR 1910.1200). An information and training-assistance packet, complete with an interactive computer disk program, has been prepared for laboratory supervisors. Eight additional videotapes show the supervisors and employees how to ensure that hazards are communicated uniformly in labels, signs, and other warning media. By availing themselves of these materials, line supervisors can satisfy each information and training requirement. Training time varies by department. 
An integral part of the Corporate Chemical Hygiene Plan is the use of engineering controls for mitigating hazards. General ventilation, laboratory hoods, and local exhaust systems are the primary means of controlling the hazards of laboratory vapors. Administrative control of the acquisition, use, and storage of chemicals minimizes the risks of fluids and solids. However, engineering and administrative controls cannot always guarantee that a chemical hazard has been eliminated. Therefore, personal protective equipment (PPE) remains an important last line of defense. PPE requirements are detailed in the procedure.

This model program is designed to be operated by the normal complement of personnel and material resources found in a well-staffed and well-equipped laboratory.

For a three-ring-bound, comprehensive description of this model program, call Ed Patigalia, OSHWPP Program Manager, U.S. Department of Energy, EH-51, at (301) 903-3972.

For answers to specific questions about SNL's Laboratory Standard Program, call Steve Parker, Model Program Principal Contact, at (505) 844-3665.

For additional information about this model program, call Gene E. Runkle, U.S. Department of Energy-Albuquerque Operations Office, at (505) 845-5087.

Points of

Contact

\section{Hazard Abatement and Control}

\section{Resources}




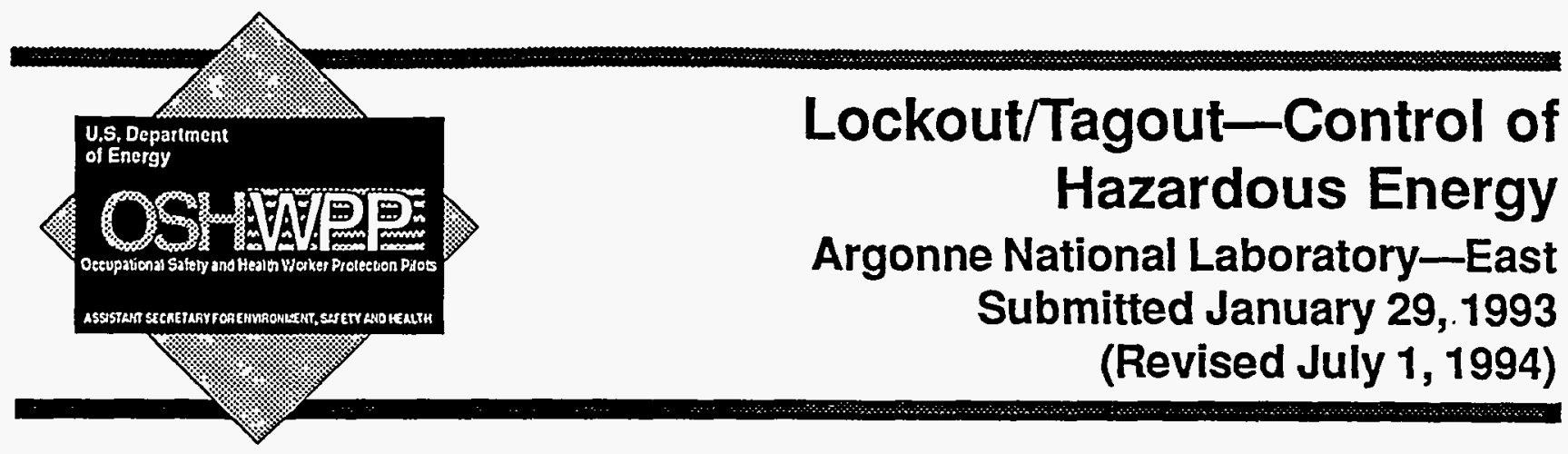

Prior to October 1990, each division within Argonne National Laboratory-East (ANL-E) developed and maintained its own lockout/tagout (LO/TO) procedures and hardware. As a result procedures varied from division to division. In a move to unify these programs, ANL-E launched an effort to design a standardized, workable LO/TO program that would fully meet U.S. Occupational Safety and Health Administration (OSHA) and U.S. Department of Energy (DOE) requirements and, at the same time, adhere to sound practice.

ANL-E's LO/TO program, administered through its Environment, Safety, and Health (ESH) Division, includes standardized training and LO/TO procedures for testing equipment, controlling energy, and monitoring the program's effectiveness. By June 1994, ANL-E had established 135 fully operable LO/TO stations throughout the facility. Each station has either 10 or 20 red-banded locks; several multiple-lockout devices; a logbook, complete with a ready-reference copy of the site's LO/TO procedures; an ample supply of tags; and plastic ties with which to attach them.

The key to the success of the LO/TO program is the clear, step-by-step procedures carefully designed for each responsible individual. There is a service/maintenance LO/TO procedure that uses the red-banded lock, and an administrative LO/TO procedure for extended lockouts, which uses notice tags and any type of lock except the red-banded lock. ANL-E also has a protocol for supplemental LO/TO procedures to fit unique situations. Finally, ANL-E clearly defines the consequences for violating this LO/TO safety procedure in the Human Resources Policy Manual (as it does for all ESH procedures at the laboratory).

The program has been determined to be strong, useful, and transferable. Other sites are encouraged to adopt it in whole or in part.

While developing its LO/TO program, ANL-E acknowledged that some equipment may have to be locked out for extended periods. It was recognized that when workers would see the same tag in the same place day after day, they might become indifferent to its waming or undervalue its importance.

\section{Program Summary}

\section{Noteworthy Practice}




\section{Policies and Procedures}

\section{Management Commitment}

\section{Employee Involvement}

To avert this reaction, ANL-E made two modifications. First, ANL-E established an "administrative" LO/TO category. A tag so classified would use its own distinctive color. In this way, the equipment or condition would be protected, and the seriousness and integrity of LO/TO would be maintained. Second, ANL-E devised supplemental procedures to cover unique situations, which require the standard LO/ TO lock and tag. The "working hot" procedure could be blended with standard LO/ TO to cover special conditions that periodically develop in research laboratories.

ANL-E's ESH Manual, distributed laboratorywide, defines the performance requirements for LO/TO. The LO/TO procedure is also imparted to employees through a comprehensive training program, required for all employees who may have to use $\mathrm{LO} / \mathrm{TO}$. The consequences for violating this procedure-which range from letters of reprimand to dismissal-are clearly defined in the ANL-E Human Resources Policy Manual.

The LO/TO procedure sets forth a series of steps for controlling hazardous energy in equipment safely and efficiently. In clear language, the steps define a series of actions to be taken by each responsible person. At the core of the procedure is the specially designed yellow and black LO/TO station, containing all necessary hardware and administrative documentation. The LO/TO procedure is evaluated and reviewed annually to ensure that it continues to be applicable and to comply with changing regulations.

ANL-E's management has made safety its first priority. As the LO/TO program was being developed, the director personally held safety discussions with large groups of laboratory employees to establish a dialog. The procedures were fully described, and their implications made clear, to safety coordinators throughout the site. The program has been widely promoted in newsletters and other laboratory publications. First-line supervisors are responsible for ensuring that machinery and equipment in their area have been properly locked out and tagged. Toward this end, the supervisors inspect their areas monthly, documenting their findings.

ANL-E employees helped develop the LO/TO program by serving on the Electrical Safety Committee. The diverse committee comprises personnel from electronics, building maintenance, the line crew, facility planning and engineering, the fire department, the scientific community, and the ESH Division. Before being implemented, the program was reviewed by a second diverse group of employees, then reviewed throughout the laboratory. Before being launched on a broad scale, the program was tested in a pilot program. As expected, the pilot employees found inaccuracies and inconsistencies that had slipped through the earlier reviews. These "bugs" were resolved, and the program was implemented laboratorywide.

The program is continually modified in response to employee feedback, near-miss and accident investigations, and DOE's Occurrence Reporting and Processing System. 
The Lockout/Tagout program ensures that all authorized employees receive the required training prior to performing LO/TO operations. Lesson plans, available in the model program comprehensive description, are periodically reviewed by technically qualified persons and safety professionals to ensure that they comply with regulatory requirements. ANL-E has trained or retrained more than 1,900 employees. Elements of the program are included in job performance and job practice training.

Hazards are detected by employees and their supervisors and brought to the attention of the ESH Division for evaluation. Suggestions for appropriate controls are made at that time. In addition, ANL-E's electrical safety procedure designates the circumstances under which "working hot" is permitted. It is the laboratory's general policy that no equipment be "worked hot" if it can be deenergized and locked out. When the general LO/TO procedure is insufficient, the program provides for other specific ways to control energy. When "working hot" is necessary, ANL-E requires specific personal protective equipment.

The laboratory has an abundance of trained, qualified professionals to implement safety and health programs and practices. The ESH Division, the Plant Facilities and Services Division, and the laboratory's Electrical Safety Committee prepared this program. Sites interested in adopting the program may be similarly staffed or may use present staff in redefined or ancillary tasks. Line personnel should be specifically appointed to control and maintain the LO/TO stations and present training sessions.

To ensure that the program is implemented smoothly, a site will require adequate supplies of locks, multiple lockout devices, tags, storage cabinets, training manuals, and other materials, as specified in the procedure; and equipment already designed and rendered (or renderable) and capable of being locked.

For a three-ring-bound, comprehensive description of this model program, call Ed Patigalia, OSHWPP Program Manager, U.S. Department of Energy, EH-51, at (301) 903-3972.

Hazard Abatement and Control

\section{Resources}

\section{Points of Contact}

For answers to specific questions about Argonne's Lockout/Tagout Program, call Sigmund (Sig) Nelson, ESH Division Electrical Safety Engineer, at (708) 252-4785.

For additional information about this model program, call Angela C. Harvey, U.S. Department of Energy-Chicago Operations Office, at (708) 252-2270. 


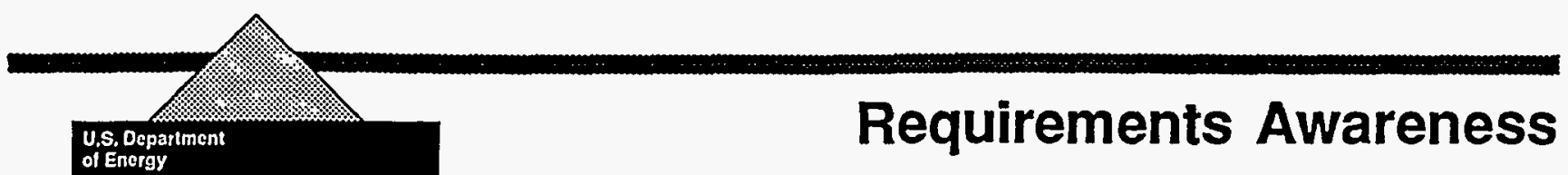

Lockheed Idaho Technologies Co., Inc. (LITCO) Idaho National Engineering Laboratory (INEL) Submitted December 2, 1992

The Requirements Awareness Program (RAP) was designed at the Idaho National Engineering Laboratory (INEL) to help first-line managers understand how to comply with environmental and safety Orders and regulations, and with quality guidelines. Developed in 1989 by EG\&G Idaho, the program was maintained until mid1993 under a myriad of constantly changing requirements. Subsequently, the program was turned over to INEL's new management and operating $(M \& O)$ contractor, Lockheed Idaho Technologies Company (LITCO). LITCO recognized the value of such a program to coexist with the company's existing organizational structure, documentation hierarchy, and management system. Accordingly, the company quickly targeted RAP for upgrading to meet these changing times.

Note: Because of ongoing revisions, RAP is currently not in operation; it will resume when the upgrading is completed. The RAP binder describes an earlier version of the program. However, LITCO's program contact will be more than happy to answer questions from interested sites.

Presented as a menu of modular, single-topic workshops, the complete program covers nine disciplines: emergency preparedness; environmental protection; fire safety; industrial hygiene; safeguards and security; industrial safety; nuclear safety; quality; and radiological control. For each discipline, requirements are presented at a basic level that addresses activities allowing modest application and an advanced level for activities that require more extensive application.

Participants enroll only in the sessions they need, on a timetable that suits their work schedules. Because different line managers hold different responsibilities, completing the program can take as few as 40 hours or as many as 106. LITCO's own policy and requirements manuals served as the main texts. For reference materials, participants use Department of Energy Orders and Federal, State, and local regulations. They also use a reference list of requirements, called a RAP checklist. At the end of the workshop, they use the checklist to create a list of requirements tailored to their organizations.

\author{
Program \\ Summary
}




\section{Noteworthy Practice}

\section{Policies and Procedures}

Three elements make the workshops a success. First, by using company manuals as the primary textbooks, participants leam to appreciate the value of these manuals as a management tool. Second, by identifying the compliance requirements that apply to their specific responsibilities, managers gain a sense of ownership and create a take-home product (the checklist) they could immediately use. Third, the workshop atmosphere promotes spirited discussion that highlights interface problems while providing a forum for solving implementation problems across organizations.

The program follows five basic Environment, Safety, and Quality (ES\&Q) principles: line management ownership, line management self-assessment, a planned approach, the use of cognizant professionals, and independent oversight. To ensure that managers understand the ES\&Q requirements, all first-line and group managers, as well as any support personnel designated by the department manager, must attend the RAP workshops that bear upon their responsibilities.

"Cognizant Professionals" are responsible for implementing the program in specific ES\&Q disciplines. As part of their duties, they identify applicable requirements and conduct the RAP workshops, aided by a facilitator.

Management's support for this model program was demonstrated in three ways. First, the ES\&Q Department was responsible for conducting the program and appointing Cognizant Professionals. Second, all group managers had to complete the Unit Manager Development Program, which included RAP. Third, from the inception of RAP in 1989 until the program was submitted as a model program candidate in late 1992, more than 250 individuals had undergone the RAP program -a significant investment of company time.

In 1989 two line managers, serving as volunteers, identified nearly 12,000 requirements, then developed an efficient method for imparting compliance strategies to their diverse colleagues. Their training method was tested at the first workshop, a 6 week effort that enlisted six line managers as the trial participants. The feedback from this effort was used to adjust the depth of detail in the program. Once the program was underway, participants continued to evaluate the workshops and their comments were used to improve them.

As a prerequisite for enrolling in RAP, each candidate had to undergo a participant profile. This provided the custodian of the program with a placement tool for determining the proper level of training. Before engaging in the actual workshop, participants leamed about the RAP process in an introductory session. Class size was limited to 12 to ensure that each trainee could participate in the class dialog. 
Participants were tested on general concepts and key ideas. To complete their training, they had to have their RAP checklists ratified by the presenter and had to score at least 70 on a 100 -point test. Once they successfully completed the program, their participation was entered into the company's training database.

As they reviewed the requirements with which they had to comply, managers discussed-from various departmental perspectives-strategies for controlling hazards and responding to emergencies. As a result of this cross-fertilization, participants were better equipped to abate hazards as soon as they returned to their workplace.

The main resource a site must consider is time slots in the schedules of first-line and group managers. To help participants juggle their job duties with workshop attendance, workshops were scheduled well in advance and conducted in two concurrent, staggered sessions. The company also provided a backup professional in each of the nine disciplines to support the managers' day-to-day work while they were attending the workshops. These staffing needs could usually be met by present employees serving in redefined or ancillary tasks. However, sites should appoint specific individuals to serve as an administrator/facilitator (one full-time equivalent and one 60-percent full-time equivalent); one clerical assistant (60-percent full-time equivalent); and subject matter experts to serve as presenters for the nine disciplines. In addition to being allowed to take time off to present the material, the experts should be granted ample time to prepare their presentations.

Sites are encouraged to provide the program not only to line and group managers, but also to managers serving in other capacities and to promising employees who currently are participating in management development programs. The bottom line for a successful Requirements Awareness Program is for management to let staffing levels be flexible to free managers' time to attend the sessions.

For a three-ring-bound, comprehensive description of this model program, call Ed Patigalia, OSHWPP Program Manager, U.S. Department of Energy, EH-51, at (301) 903-3972.

For answers to specific questions about LITCO's Requirements Awareness Program, call Floyd Croy, Model Program Principal Contact, at (208) 526-8790.

For additional information about this model program, call Don Michaelson, U.S. Department of Energy-Idaho Operations Office, at (208) 526-5325.

\section{Hazard Abatement and Control}

\section{Resources}

\section{Points of Contact}




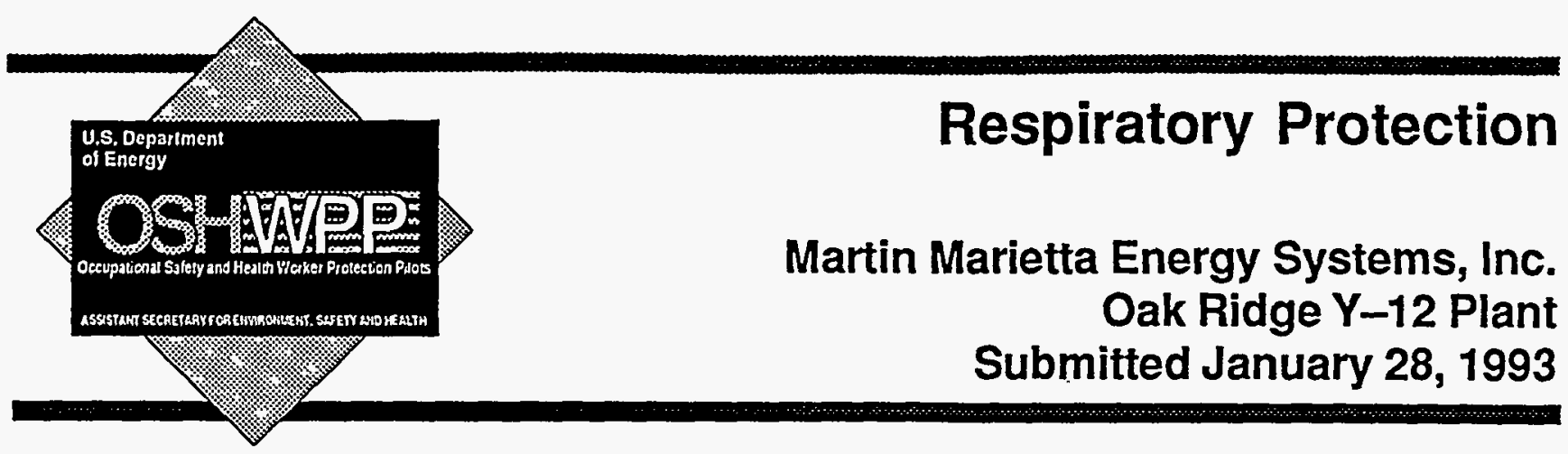

Each month, more than 2,000 workers at the $\mathrm{Y}-12$ Plant use a respirator. In developing the Respiratory Protection Program, Martin Marietta Energy Systems, Inc. (MMES) had two simple goals: (1) Reduce the need for workers to wear respiratory protection by screening the workers and installing engineering controls; and (2) when respiratory gear must be wom, make sure it is used properly.

A key part of the program's success is a series of rigorous standards for issuing, cleaning, and repairing respirators. By following these standards with the aid of specially developed software, MMES reduced duplication of effort and curbed inventory of parts, saving the $\mathrm{Y}-12$ Plant more than $\$ 2$ million in the program's first 2 years.

The program fully complies with national consensus standards, U.S. Occupational Safety and Health Administration (OSHA) standards, U.S. Department of Energy (DOE) Orders, and good industrial practices.

The program has consolidated plant procedures while clarifying how they relate to one another. By coordinating a complex array of procedures to ensure respiratory protection across a large facility, MMES has created a model program for the DOE weapons complex. Other DOE facilities are encouraged to measure their existing respirator programs against this one and adopt the portions that will produce improvements.

The program policies are readily understood from the purpose, scope, definitions, and responsibilities spelled out in the procedures. Procedures included in the model program comprehensive description cover discipline, selection of respirators, fit testing, training of respirator users and their supervisors, and surveillance.

To maximize employee protection, the $\mathrm{Y}-12$ procedures are regularly benchmarked against existing standards of OSHA, DOE, other MMES sites, and good industrial practice. Because $\mathrm{Y}-12$ workers face exposure to asbestos, lead, and beryllium as well as the usual assortment of heavy metals, carcinogens, and solvents, the risks of a poor-fitting respirator justify these comparisons.

\section{Program \\ Summary}



Management
Commitment

\section{Employee Involvement}

\section{Training}

\section{Hazard Abatement and Control}

Management participates in all formal audits and surveillances held within their geographic domain of responsibility. They also conduct self-assessments to identify deficiencies or points of noncompliance. If any type of assessment results in a finding, managers must respond rapidly with corrective actions.

Program participants and leaders receive letters of recognition. Management further shows its commitment by budgeting time for the activities of the Five-Plant Respiratory Protection Committee and the Y-12 Plant Respiratory Protection Committee, and by holding respiratory protection meetings with respirator issuers and trainers.

The Y-12 Plant Respiratory Protection Committee is composed of personnel from all areas of responsibility who are involved in the use of respirators. The committee sets policy and approves all changes to current procedures. Employees provide feedback to the committee and to the Industrial Hygiene Department by submitting safety suggestions, participating in near-miss investigations, and participating in the monthly meetings. The meetings routinely draw as many as 90 issue-point personnel, plant trainers, and health and safety professionals.

The respirator program involves some 200 persons, linked by electronic mail for rapid communication. Before the program launch, affected personnel from each organization were asked to review it and validate the sections that affected their operations.

Like the procedures themselves, training requirements are based on existing standards from OSHA, DOE, and MMES, and on good industrial practice. All training courses are designed to ensure that employees not only understand their responsibilities but can perform them. Specialized training is given to respirator users, their supervisors, the issue-point administrators, the breathing-air-cylinder inspector/testers, and the respirator fit-test administrators.

The issue-point administrator must undergo the same 4-hour training course as the supervisor of a respirator user. The user is trained for 1 to 1.5 hours in a basic course; additional instruction hours are provided to cover specific types of respirators, as needed. Copies of the lesson plans are included in the model program.

The hazards controlled or abated by this program include not only the airborne contaminants, but also the heat stress that can arise from unnecessary respirator use in a hot area and the contamination or oxygen deprivation that can arise from improper respirator use or fit. By implementing a standardized program and involving numerous site personnel, MMES has been able to rely on engineering controls in many situations, making respirators unnecessary. 
When a hazard cannot be abated immediately, interim protective measures are specified. These measures can range from a variance from the one-time-use rule to administrative control of the potential exposure time. The hazard abatement methods are described in the model program comprehensive description.

Personnel resources to develop the program were available within the $\mathrm{Y}-12$ Plant staff. All development was completed by the well-qualified personnel of the various involved departments.

Facilities or sites planning to adopt part or all of this model program may find, as Y-12 did, that they can meet their needs by having present staff serve in redefined or ancillary roles. Certain specific positions, however, must be filled: a respirator program coordinator, breathing-air-cylinder inspector/testers, centralized respirator cleaners, repair and inspection personnel, and respirator issue-point administrators.

In addition to providing qualified personnel, sites wishing to implement the program smoothly should define their respiratory protection needs; assemble copies of all relevant regulations, Orders, and guidelines as source documents; and provide facilities for testing respirator quality and fit. For the latter purpose, MMES has developed a software-based fit-test procedure.

For a three-ring-bound, comprehensive description of this model program, call Ed Patigalia, OSHWPP Program Manager, U.S. Department of Energy, EH-51, at (301) 903-3972.

For answers to specific questions about MMES's Respiratory Protection Program, call M.H. Burnett, Y-12 Industrial Hygiene Department, Model Program Principal Contact, at (615) 576-6461.

For additional information about this model program, call Kenneth F. Leifheit, U.S. Department of Energy_ER/DP Oak Ridge Operations Office, at (615) 576-0835.

\section{Resources}

\section{Points of Contact}




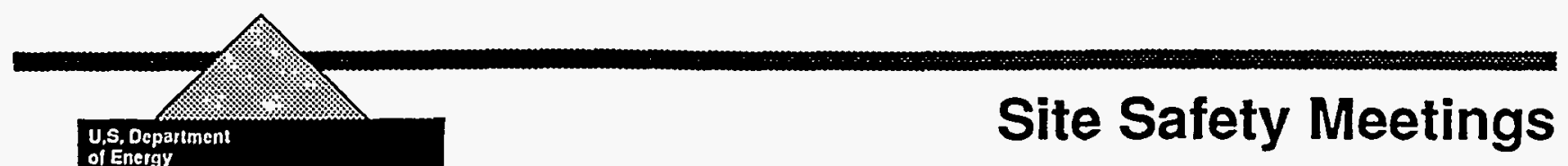

Since the Savannah River Site began operating in 1944, the Site Safety Meeting Program has been developing and functioning. As currently run by Westinghouse Savannah River Company, Inc. (WSRC), the program involves all employeesfrom the company president to the latest new hire or subcontractor. The program not only involves them, it requires their commitment.

The program establishes safety committees tailored for the various levels of management. There are eight permanent subcommittees, each representing a major functional area. At the highest level is the Central Safety Committee, comprising the president, the president's staff, the chairs of the site area safety committees, and the chairs of the permanent subcommittees. Each committee and subcommittee convenes once a month, or more if conditions warrant.

Because the Savannah River Site is so vast (covering more than 300 square miles) and its operations so varied, safety committees are organized not only by function and level but by geographic work area. Each work area's central safety committee comprises three permanent subcommittees as well as representatives from all of its functional safety committees. When a problem is brought up or resolved, the committee's chair presents the problem or resolution to the Central Safety Committee. In this way, no safety concern is more than two steps removed from the highest level of attention.

The submittal includes copies of the site policies defining personal responsibilities and commitments for each employee; the exact responsibilities depend on the employee's position in the corporation. Also found in the submittal are copies of typical minutes from committee meetings; injury reports; audit schedules; and inspection reports.

The Employee Safety Manual 8Q, Procedure 2, develops the structure, functions, and responsibilities of the safety committees. The Site Central Safety Committee, which is responsible for coordinating the safety program, has eight permanent subcommittees (Policy Review, Traffic, Occupational Health, Emergency Preparedness, Off-the-Job Safety, Safety Activities, Housekeeping, and Safe Distribution). Chaired

\section{Program Summary}

\section{Policies and Procedures}


Management Commitment

\section{Employee Involvement}

\author{
Training
}

\section{Hazard Abatement and Control}

Resources by the WSRC president, the Central Committee consists of the company's senior staff, selected staff members, chairs of the Area Central Safety Committees, the Manager of Construction Safety, and the Manager of the Industrial Safety Section, who serves as secretary.

There are nine Area Central Safety Committees; each has three standing subcommittees: Emergency Preparedness, Off-the-Job Safety, and Occupational Health. Committees may set up additional subcommittees, should conditions warrant. The area subcommittee has jurisdiction over everyone who enters the geographic area.

Each division, department, section, or group must develop and implement an annual safety program. The programs form the basis for setting training goals, deciding on safety-meeting agenda, and investigating injuries and incidents.

Management's commitment to the safety meetings is evidenced by the large number of hours devoted to reaching the goals set at these meetings. Within each department, higher-level managers are expected to conduct some of the all-employee meetings and to serve on the Area Central Safety Committees.

Employees participate in the safety meetings as well as the area audits. Some employees are selected to serve on their Area Central Safety Committees.

At new-employee training, everyone is made aware of how the site safety committees are structured and how they operate. Once onboard, each employee or contractor participates in the department's monthly safety-training meetings. As hazards are identified and incidents investigated, managers must respond by identifying domains in which their employees could benefit from further training.

Supervisors or managers, together with their safety and health support personnel, are responsible for detecting hazards by inspection, investigation, inventory process analysis, and review. The safety committees, in tum, review the results of their efforts. Because they encompass a broader range of workers, it falls to the committees to test the solution, endorse it, and communicate it throughout the site.

This program can function only if all the management, safety, health, and employee resources are fully committed. In its Employee Safety Manual, WSRC strives to ensure this commitment by requiring each employee to engage in a one-on-one discussion with his or her immediate supervisor, then sign a Personal Safety Commitment Pledge. 
For a three-ring-bound, comprehensive description of this model program, call Ed Patigalia, OSHWPP Program Manager, U.S. Department of Energy, EH-51, at (301) 903-3972.

For answers to specific questions about WSRC's Site Safety Meeting Program, call Lisa Skinner, Model Program Principal Contact, at (803) 644-5653.

For additional information about this model program, call Roger D. Rollins, U.S. Department of Energy - Savannah River Operations Office, at (803) 725-3956. 


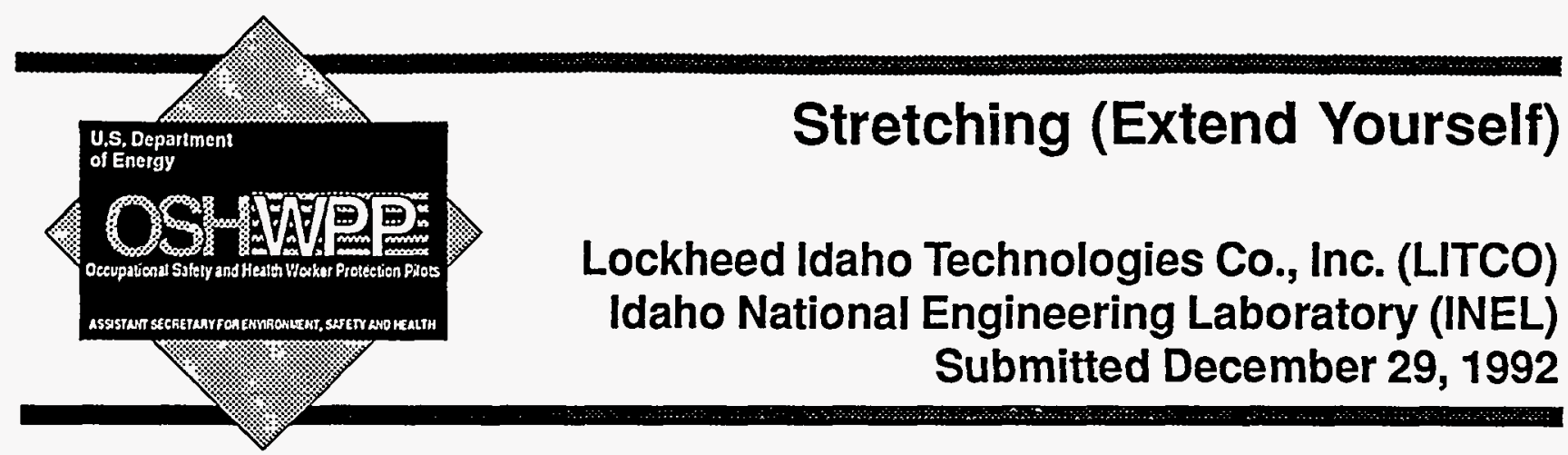

Extend Yourself is a stretching regimen that improves muscle tone in the neck, back, spine, legs, and arms while curbing work-related injuries caused by sprains and muscle strains. The stretches are performed for 5 to 10 minutes at the start of each

Program Summary workday.

Over a recent 5-year period, strains and sprains accounted for one of every three reported injuries throughout DOE and 35 percent of the cost. Extend Yourself was launched by EG\&G Idaho in October 1990 to reduce the high frequency of sprains and muscle strain injuries throughout the Idaho National Engineering Laboratory (INEL). The program is now maintained by the site's new operator, Lockheed Idaho Technologies Company (LITCO). Though originally targeted at employees working in warehouses, laundries, and cafeterias, the program proved so beneficial that employees in bus maintenance and other domains asked to participate. In addition to providing a range of physiological benefits, the stretching has given employees greater self-esteem and mental alertness while reducing stress.

A voluntary program run by LITCO employees, Extend Yourself is supported by the Environment, Safety, and Health Group. Before an employee group begins the program, its worksite is evaluated by medical, safety, or health personnel, accompanied by the employees. Together they select exercises and determine whether any specific processes may call for special stretches or longer periods of stretching to avert injury.

Wherever the program has been adopted, employees are experiencing significantly fewer muscular injuries. Beyond the physical benefits, employees are more productive, more safety-conscious, and more willing to collaborate. Moreover, relations between managers and employees have improved.

Submitted in December 1992 to be considered as an OSHWPP pilot program, Extend Yourself was recognized as a unique approach to controlling a common hazard. Safe, simple, low-cost, and effective, this model program can readily be adopted by any site or facility, yielding significant savings in lost workdays and workers compensation outlays. 


\section{Policies and Procedures}

\section{Management Commitment}

\section{Employee Involvement}

\section{Training}

\section{Hazard Abatement and Control}

Resources
The policy statement is found in the Safety Policy Statement, which appears in the company's safety manual. The submittal sets forth a recommended procedure for getting management approval.

The support and commitment of management are evidenced by the program's inclusion in operational activities. Line managers stretch together with their workers. In addition, if a group of employees decide to join the program, their line manager is accountable for implementing the program, ensuring that new employees are trained, and seeing that the program, once in place, continues without interruption.

As an employee-run program, Extend Yourself relies completely on the employees. Employee comments and suggestions were used to improve the initial program. They continue to be used in this way while providing positive reinforcement as a new group is being trained.

The submittal explains the procedure for training a group of employees to do the stretches. The single training session lasts about an hour, in the first half, employees learn about the muscle groups they will be stretching; in the second, they are led through the exercises. Their attendance at the training meetings is documented and input into the Company Training Inventory System.

When a new group begins, a facilitator serves as the exercise leader until a permanent exercise leader is chosen from the group. This exercise leader must understand the effects of stretching and the appropriate muscle groups to be exercised.

Because this model program falls somewhat outside the usual concept of safety programs, it is not governed by any regulatory or good-practice requirements.

The mandatory training session is designed to ensure that each employee performs the stretches in a safe manner. Once the program is underway, the exercise leaders observe their co-workers to make sure they are stretching in a safe manner. As a further safeguard, participants are periodically observed by health and safety professionals.

At most sites, the program can be launched and maintained by existing staff serving in ancillary roles. The only specific roles that must be filled are an Extend Yourself Program facilitator and an exercise leader drawn from each worksite's employee group. Handouts, including photos showing the correct way to stretch, should be used so that employees firmly understand how the exercises should be performed 
and why it is to their benefit to perform them each day. (The comprehensive program description includes a series of photos.) Also needed are a videotape to demonstrate the exercises (produced inhouse by LITCO); a VCR and video monitor to play the demo tape; and space for the group to do the exercises each morning. The exercises can safely be performed without a mat or special clothing.

For a three-ring-bound, comprehensive description of this model program, call Ed Patigalia, OSHWPP Program Manager, U.S. Department of Energy, EH-51, at Points of (301) 903-3972.

For answers to specific questions about LITCO's Extend Yourself Program, call Delwin Allred, Model Program Principal Contact, at (208) 526-2639.

For additional information about this model program, call John Martin, U.S. Department of Energy-Idaho Operations Office, at (208) 526-1386. 


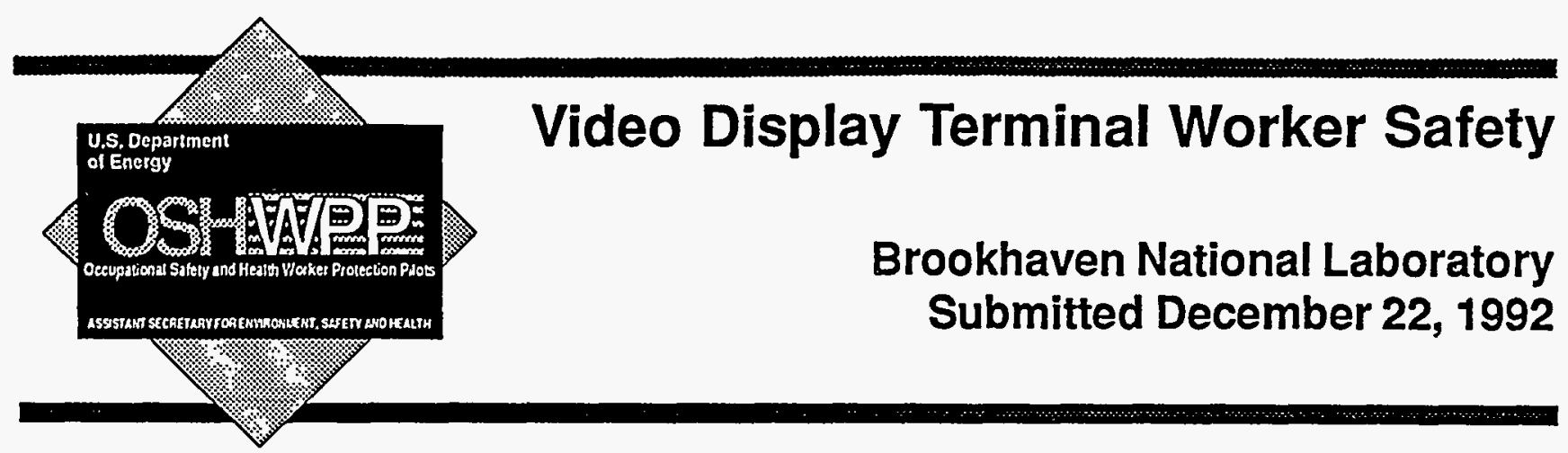

In 1986, as an informal part of overall workplace evaluations, Brookhaven National Laboratory (BNL), Upton, NY, began studying workplace video display terminals (VDT's). The purpose was to evaluate two kinds of hazard: electromagnetic nonionizing radiation and poor ergonomic design. This initial effort uncovered a large number of problems. As a result, in 1991 management launched a VDT Worker Safety Program. A key element is a VDT workstation evaluation form. Developed by BNL industrial hygienists, the form provides a simple, standard way for employees to measure and describe their workstations. At the same time, two training sessions were created to teach employees about the ergonomic (musculoskeletal), radiological, and visual hazards of computer workstations.

In the first session, key employees learn how to use the standard form to conduct preliminary workstation evaluations. Completed forms are turned in to the Safety and Environmental Protection (S\&EP) Division. There, they are reviewed by an industrial hygienist. If one or more workstation measures reported by the employee are ergonomically unacceptable, the industrial hygienist examines the workstation firsthand.

In the second training session, affected employees leam about common VDT hazards. This 1.5-hour session describes the hazards, explains how they affect the user's physiology, suggests corrective measures and equipment, and demonstrates ways to prevent or lessen the hazards.

The program has met with great success. BNL submitted the program for consideration as an OSHWPP pilot program in the hope that other facilities would adopt it.

By policy, BNL pursues proactive ways to comply with current and proposed legislation conceming VDT ergonomics and emissions. Toward this end, BNL issued procedural guidelines recommending that all employees who spend at least 50 percent of their workweek at a VDT participate in the VDT Worker Safety Program. This precautionary approach is significantly more conservative than the measures required by current Federal and State laws and regulations. The guidelines follow a proposed local ordinance.

\section{Program \\ Summary}


Management Commitment

\section{Employee Involvement}

In a memorandum, the Directorate of the Laboratory provides a guide to computer workstation design and instructs managers to authorize as much time to determine how a workstation should be configured as they authorize to select computers and software.

While BNL has evaluated all applicable workstations, management supports an ongoing self-assessment program: If any workstation is found to be out of compliance, the deficiency must be promptly corrected. Through information bulletins and other materials, employees are regularly apprised of hazards and of ways to make their workstations safer.

By the end of October 1994, VDT workstation training had been provided to 407 employees from more than three-fourths of BNL's divisions and departments, as well as to several employees from DOE's Brookhaven Area Office.

Although training is voluntary, participation is strongly recommended for all employees using VDT's for more than half of their workweek. Employees facing less intensive exposures are also welcome. The interactive format of the 1.5-hour training session is designed to encourage employees to ask questions and share their experiences. They are encouraged to evaluate their workstations and are given the names of site contacts for information or assistance.

The main goal of the VDT training is to help employees recognize hazards in their current workstations and understand how to modify their workstations by adjusting their chairs, desks, copy stands, lamps, and other equipment. Employees learn how to use readily available aids, such as footrests. Alternatively, they are encouraged to seek help from a BNL industrial hygienist, who can evaluate the workstation and recommend corrective measures.

A second training goal is to show employees how to maintain proper body posture and take breaks to exercise and rest. Employees leam how their anatomy-for example, the length of their limbs and the limited range of motion of their necks and backs-dictates how their workstations should be configured. Armed with such knowledge, they can quickly determine how their own workstations must be modified.

For those workers whose job assignments are clerical or involve VDT use instead of chemical exposure, VDT workstation training can be substituted for Chemical Hazard Communication.

The trainees are not graded; however, participants complete an exam. 
A major theme of the training program - and the workplace evaluations that followis the importance of using engineering controls to improve workstation design. Should such controls be lacking, BNL provides personal protective equipment, including cushions, copyholders, supports, ergonomic chairs, footrests, ergonomic workstations, wristrests, and glare filters. The items are "advertised" through a memo that describes them and explains, through words and pictures, how to use them.

The S\&EP Industrial Hygiene Group provides the technical support for the VDT Worker Safety Program. This group includes Certified Industrial Hygienists and other personnel who have been trained in the hands-on aspects of ergonomic evaluation and measurement. At other DOE sites, program staffing needs can be met by present staff serving in redefined or ancillary tasks. Sites are encouraged to specifically appoint a VDT training program coordinator and ergonomic evaluators.

For a three-ring-bound, comprehensive description of this model program, call Ed Patigalia, OSHWPP Program Manager, U.S. Department of Energy, EH-51, at (301) 903-3972.

Hazard

Abatement and Control

Resources

For answers to specific questions about Brookhaven National Laboratory's Video Display Terminal Worker Safety Program, call Robert Selvey, Model Program Principal Contact, BNL Safety \& Environmental Protection Division, at (516) 282-3066.

For additional information about this model program, call Carson Nealy, U.S. Department of Energy-Brookhaven Area Office, at (516) 282-3424. 


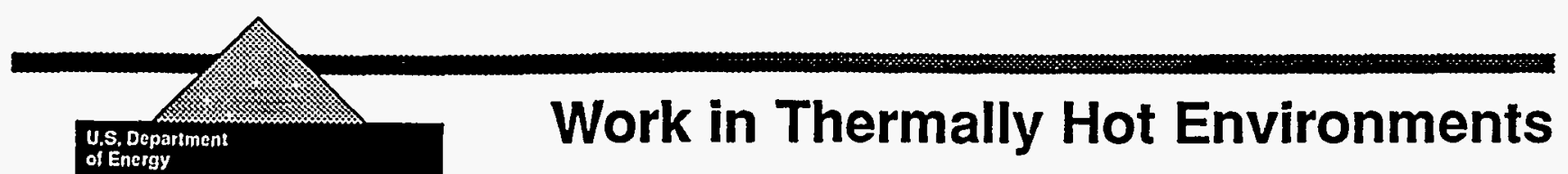

\section{Lockheed Idaho Technologies Co., Inc. (LITCO) Idaho National Engineering Laboratory (INEL) Submitted December 23, 1992}

Individuals suffering from heat stress may not immediately exhibit physical symptoms, but may suffer from impaired mental judgment, rendering them incapable of working safely. Recognizing that heat stress can be extremely serious, Westinghouse Idaho Nuclear Company (WINCO) developed the Work in Thermally Hot Environments (WTHE) program. The program is now maintained by Lockheed Idaho Technologies Company (LITCO), which has expanded the program to encompass all employees it absorbed on becoming the operating contractor for Idaho National Engineering Laboratory (INEL). Designed to minimize the heat loads incurred when working in a hot environment while wearing protective clothing, the program provides flexible guidelines that account for variations in the workplace, the task, and the employee's ability to handle heat stress. In this way, supervisors can exercise broad discretion in planning, scheduling, and monitoring the duration of work in thermally hot environments.

The program was derived from procedures used to control heat stress at GPU Nuclear's Three Mile Island (TMI) commercial nuclear plant in Pennsylvania. WINCO enhanced the TMI procedures by applying recommendations from the Electric Power Research Institute and the American Conference of Governmental Industrial Hygienists. The program is continually being fine-tuned by incorporating the findings of industry studies on work-stay guidelines, and by studying historical data from personal heat stress monitors worn by LITCO employees.

Included in the model program are recommendations for designing and using instruments for measuring personal and area thermal loads. Also included are data from research and training experience. The training materials, included in the comprehensive program description, can be readily adapted to any site.

The LITCO heat stress program was recognized as exemplary. Because of its scope and flexibility, it is highly recommended for adoption or adaptation by other DOE facilities.

Two elements of the program were deemed exemplary. First, LITCO medically evaluates how effectively and safely each worker can function in a thermally hot environment. Supervisors use these evaluations, together with assessments of the

\section{Program Summary}

Noteworthy Practice 


\section{Policies and Procedures}

work area and task, to tailor assignments to the individual's capacity for enduring heat stress (a function of time and temperature).

Second, the Radiation Work Permit includes a block in which the job supervisor must record the area temperature. A health physics technician then calculates and writes in the allowable stay time, basing the calculation on the heat stress table found in LITCO's safety manual.

By company policy, procedures must be designed in such a way that employees can perform their duties in thermally hot conditions without jeopardizing their health or safety. Toward this end, every employee who might be exposed to a heat stress hazard must successfully complete a training program. There, the employee leams how to recognize symptoms, how to administer first aid, and how to take protective measures.

Supervisors are responsible for teaching their workers the company's heat stress policy, assessing the task and work area, determining each individual's work/rest cycle, and processing Hazardous Work Permits for activities not covered by a heat stress control procedure. Employees who may be exposed to heat stress must advise their supervisors of any physical impairments and medical heat restrictions, follow the heat stress policy guidelines, and take appropriate action if heat stress symptoms develop.

Industrial Hygiene is responsible for updating the policy, maintaining statistics regarding exposures, and helping supervisors evaluate workplaces and tasks. For reference purposes, the policy includes definitions of three categories of heat-induced illness and associated treatments, as well as guidelines for setting heat stress work limits.

Management has made first-line supervisors responsible for ensuring that their workers comply with the policy and program, and has pledged them the support of the safety and health group. Management funded the purchase of the computerized heat stress monitors and the setup and maintenance of the heat stress database. Company managers, moreover, have assumed responsibility for inspecting thermally hot workplaces and have been trained in DuPont's Safety Training Observation Program (STOP). Under LITCO's self-assessment policy, they review the model program annually.

At the inception of the heat stress program, a committee of employees, management, and union representatives addressed concems about the program and its implementation. Employee input continues to be sought regarding the design of protective

clothing and heat stress monitors.

\section{Employee Involvement}


In 1992, WINCO management assessed the program. Employees were interviewed and encouraged to state how well they felt the program was working. Through a LITCO recommendation system, employees continue to comment on the program.

A company poster reminds employees that if they would like to be monitored to determine whether they face a high risk of heat stress, they should contact the Industrial Hygiene section, which then evaluates the work area and the workers assigned there.

While no specific regulations require that workers be trained in heat stress or heatinduced illnesses, LITCO's Industrial Hygiene section has developed a 1-hour heat stress training program. At the end of the session, employees are tested to determine whether they've leamed how to avoid hazards, identify symptoms, and alleviate high-risk situations. A copy of the training materials is included with the model program comprehensive description.

Attendance is documented in the health and safety training database. Records are periodically reviewed to ensure that everyone has received the necessary training and to identify employees whose training must be updated.

As a first line of attack against heat stress hazards, LITCO uses engineering controls to lower the ambient temperature. Concomitantly, the selection of personal protective clothing is aimed at providing adequate protection from biological, chemical, and physical hazards while minimizing the trapping of metabolic heat. To quickly reduce body temperature, vortex cooling systems and ice vests are available. In addition, body-temperature and heart-rate data-recorded by personal monitorsare used to establish endurance limits. Finally, the scheduling of work, rest, and recovery time is an integral part of the program, and associated guidelines are included in the policy.

Each supervisor is responsible for complying with the hazard control methods mentioned above. At the same time, potentially exposed employees are made aware of the control methods, their individual capacities for working in hot conditions, and the early symptoms of heat stress. In fact, the personal monitors wom by employees working in thermally hot environments provide an audible early waming when body temperature and heart rate exceed safe limits.

The heat stress program was developed by two industrial hygienists, a technician, and an administrative assistant, all working part-time. A summer intern helped evaluate and implement the program. At other facilities, these functions may be met by present staff serving in redefined or ancillary roles. Two specific roles must be filled: safety and health personnel to monitor and characterize the thermal environment, and persons responsible for monitoring work-stay times for specific tasks.

\section{Training}

\section{Hazard \\ Abatement and Control}

Resources 
Before launching a program of this kind, a site should have adequate quantities of instrumentation for measuring personal and area heat stress. Also, the site should first identify and characterize thermally hot environments.

Points of Contact
For a three-ring-bound, comprehensive description of this model program, call Ed Patigalia, OSHWPP Program Manager, U.S. Department of Energy, EH-51, at (301) 903-3972.

For answers to specific questions about LITCO's Work in Thermally Hot Environments program, call Bruce L. Hendrix, LITCO, Model Program Principal Contact, at (208) 526-7989.

For additional information about this model program, call J.A. Jones, U.S. Department of Energy-Idaho Operations Office, at (208) 526-0237. 


\section{Appendix: OSHWPP Model Programs Evaluation Criteria}

$\mathbf{T}$ he following criteria accompanied the Occupational Safety and Health Worker Protection Pilots (OSHWPP) model programs solicitation announcement to provide guidance on the nature of the information to be provided. They were developed based on OSHA's Voluntary Protection Program principles and were utilized to evaluate the suitability of safety and health programs as prospective pilots under OSHWPP. Model programs might include such subjects as medical surveillance, motor vehicle safety, and ergonomics. Those selected for piloting will be matched with those facilities having expressed interest in such safety and health areas.

There are six major areas of evaluation:

1. Policies and Procedures,

2. Management Commitment,

3. Employee Involvement,

4. Training,

5. Hazard Abatement and Control, and

6. Resources.

Each of the areas of evaluation should be addressed as it relates to the particular safety and health program element being submitted for consideration. Suggested supporting documentation is indicated for each area, but these lists should not be considered allinclusive. Other information that would aid in the evaluation of the program is encouraged.

The information is to be packaged in a three-ring binder tabbed to correspond to each area of evaluation. An introductory section should contain the following:

- the program title;

- a brief description of the program, with historical information and identification of key elements that make this program exemplary;
- a letter of commitment of support for OSHWPP from the organization submitting a nomination package for consideration; and

- points of contact for readers wishing to obtain additional information.

The evaluation criteria questions included in the following pages may be used as a guide to address the different areas. A brief response to each area of evaluation should be made, with references given to any supporting documentation provided.

Additional supporting evidence or documentation not directly related to lines of inquiry may be included under a tab labeled "additional information" placed at the back of the binder. This section may include such information as letters of commendation, a noteworthy practice citation, and other documents confirming the program's value.

This package is to be sent to the responsible field and program office for review and consideration for submittal to EH-51, which is responsible for final evaluation and selection of the programs.

NOTE: It is anticipated that the majority of OSH program element nomination package contents will consist of preexisting materials (procedures, lesson plans, memorandums, etc.). Additional text needed to address the evaluation criteria should be kept to a minimum by referencing this documentation. This additional text should not exceed 10 to 15 pages.

Specific questions may be directed to:

Ed Patigalia, EH-51

OSHWPP Program Manager

Telephone: (301) 903-3972

Fax: (301) 903-2239 


\section{Occupational Safety and Health Worker Protection Pilots (OSHWPP): Evaluation Criteria}

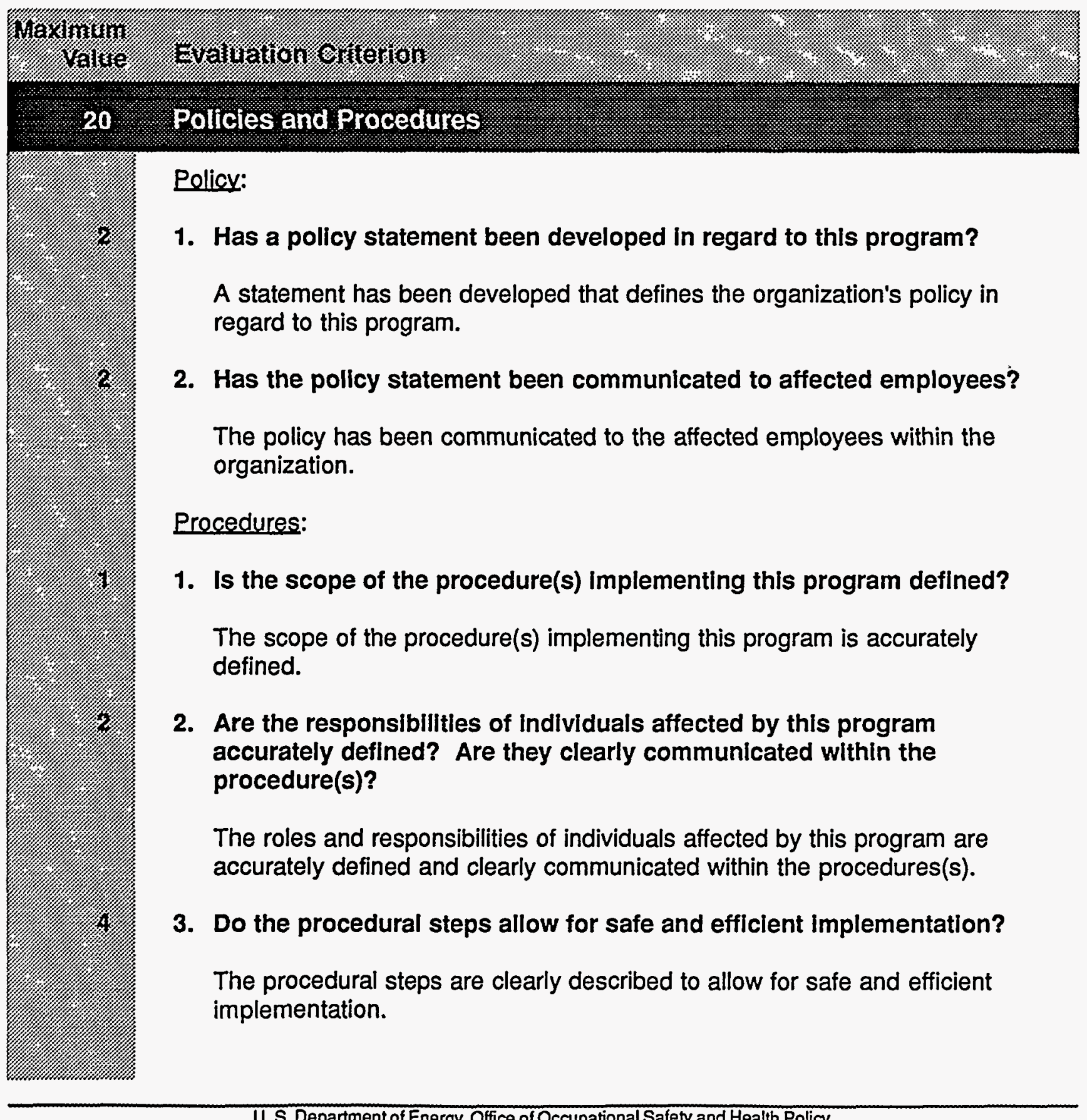




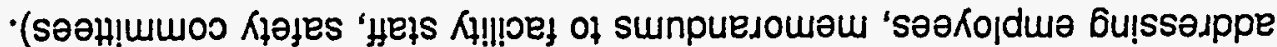

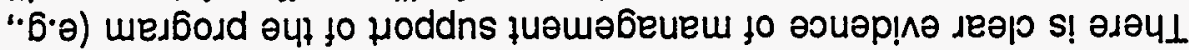

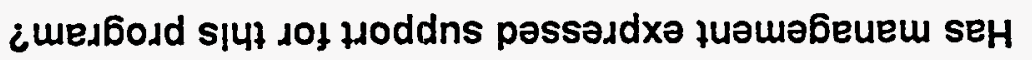

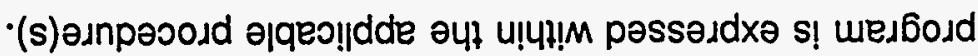

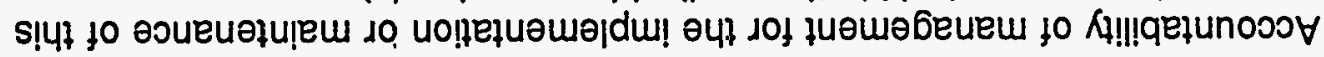

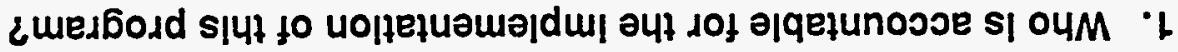

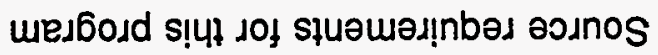

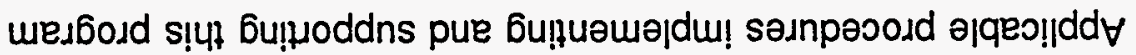

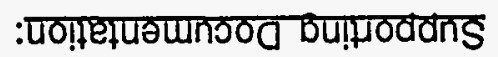

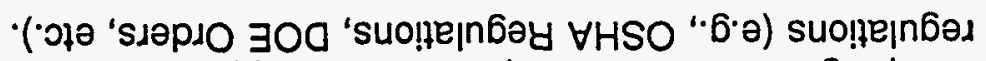

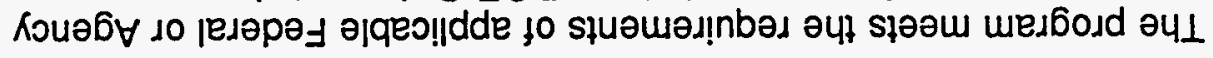

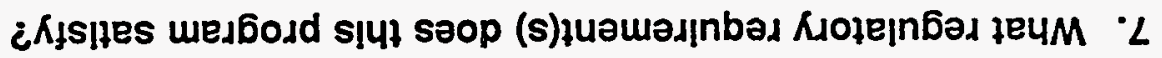

punof

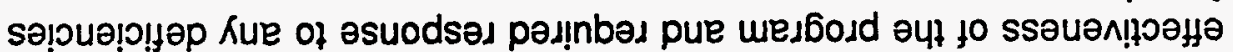

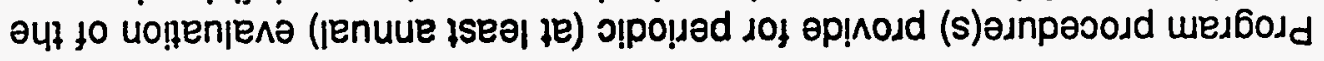

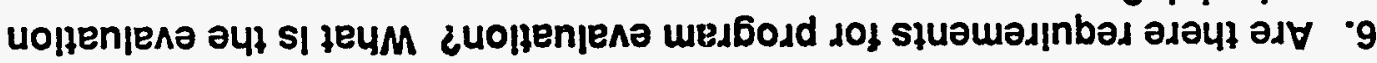

\section{¿ә|прәчэs}

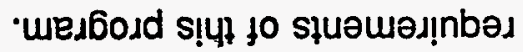

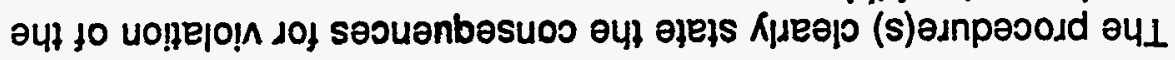

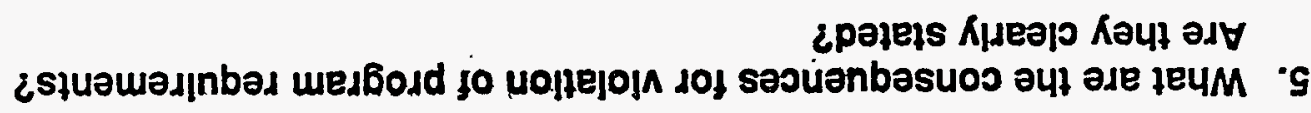

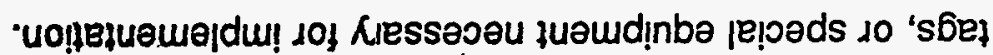

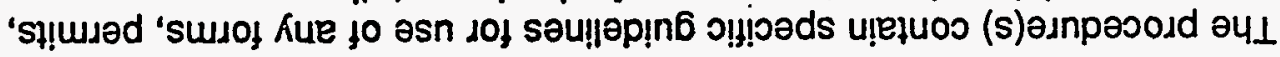

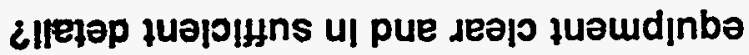

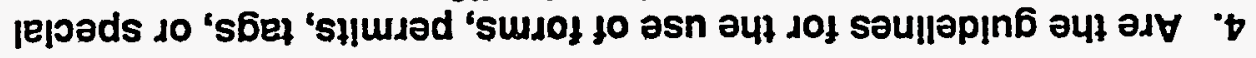


$\varepsilon L$

-səaरојduә рәюәне

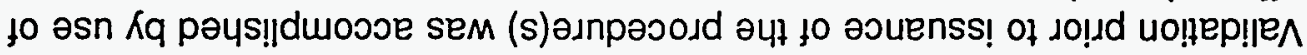

¿aouenss! of dolıd

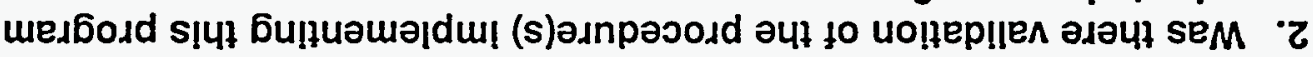

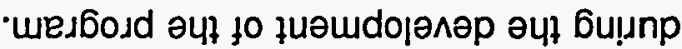

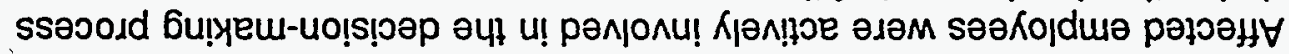

¿SOlOd

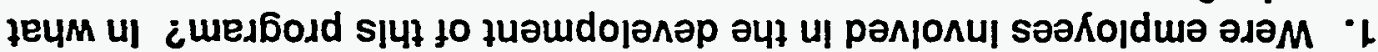

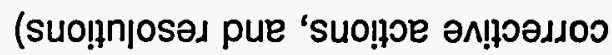

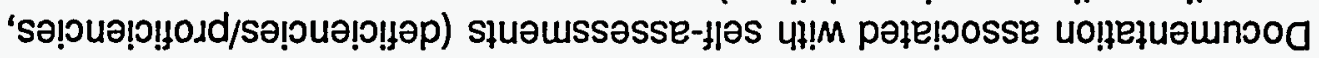

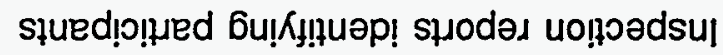

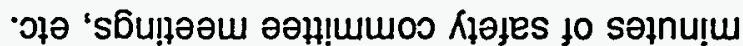

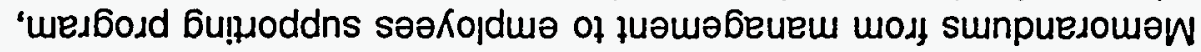

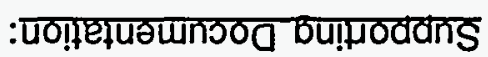

-słuaussasse әsәuł 41!m pal̨e!̣osse

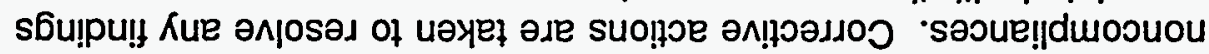

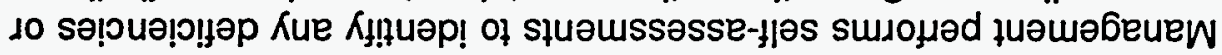

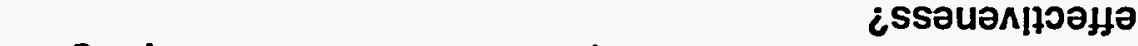

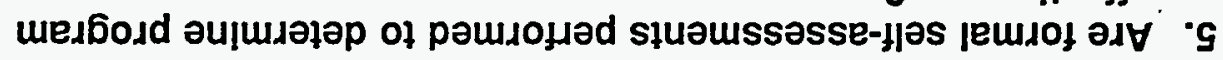

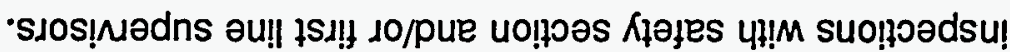

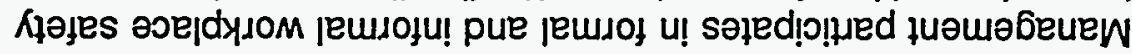

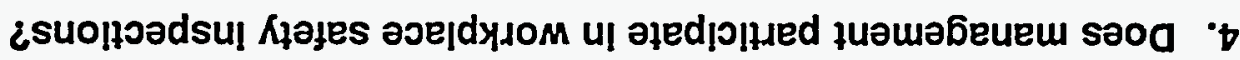

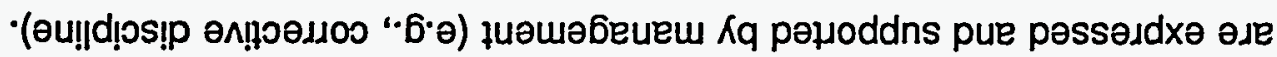

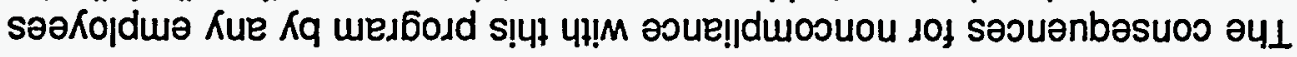

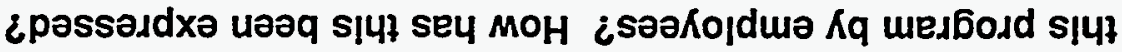

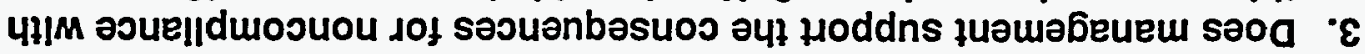


-spдezey of əגnsodxa pue 'słuəuubịse

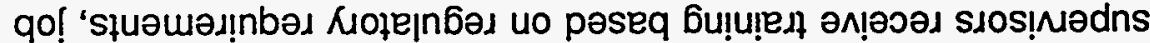

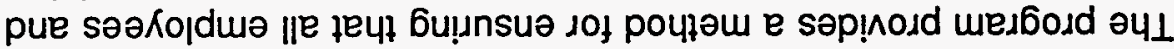

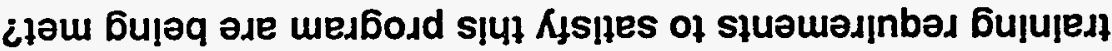

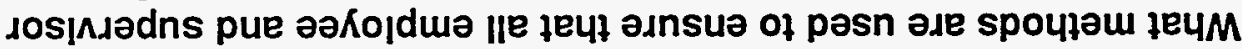

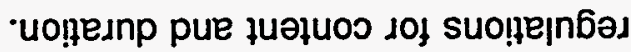

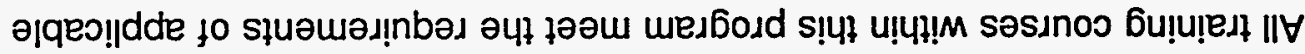

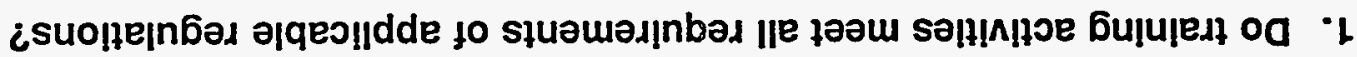
6umulex

әlqeo!

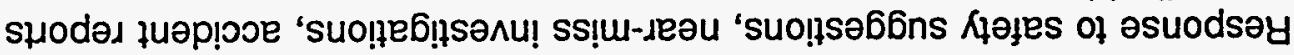

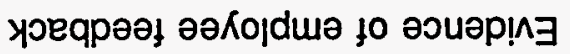

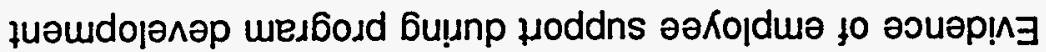

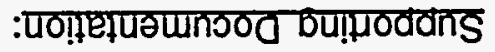

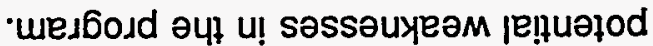
Kue K!!

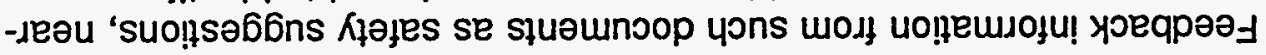

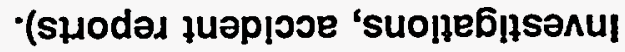

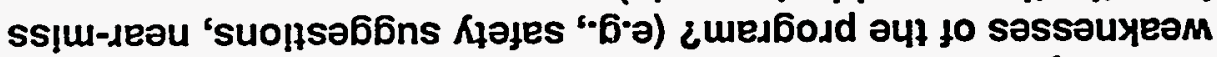

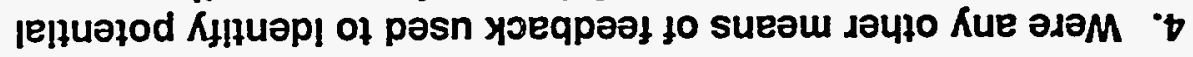

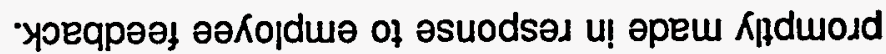

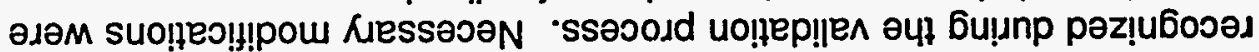

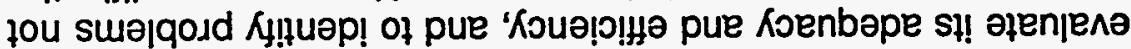

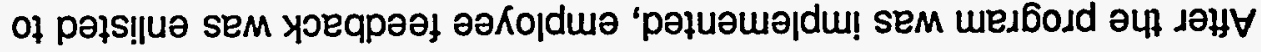

$$
\text { ¿uo|łełuourjdu! }
$$

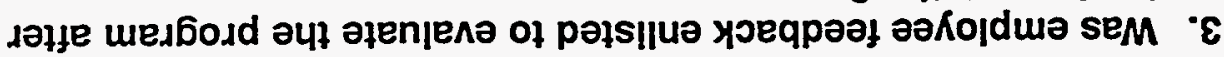




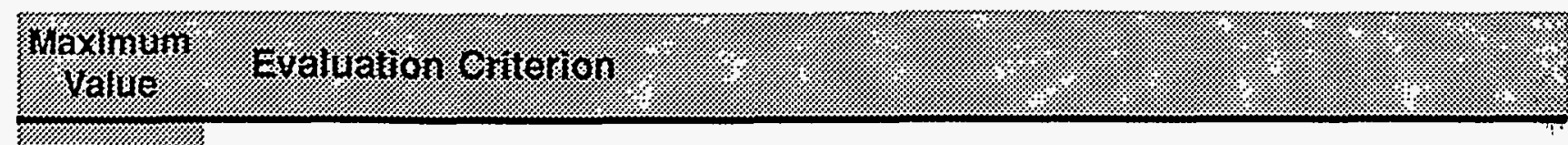

3. What methods are used to ensure that employees and supervisors are trained prior to being assigned to job duties exposing them to associated hazards?

The program provides a method for ensuring that employees and supervisors are trained prior to being assigned to job duties exposing them to associated hazards.

4. What methods are used to ensure that training documentation is retrievable and auditable?

The program requires that documentation providing evidence that affected employees have completed training be kept in a retrievable auditable manner.

5. Have lesson plans for formal training courses been reviewed by qualified Individuals for technical content and do they meet regulatory and facility-specific requirements?

Formal training classes have approved lesson plans that have been reviewed for technical content by qualified individuals and meet regulatory, as well as facility-specific, requirements.

6. What methods are used to evaluate employee and supervisor understanding of the program requirements after completlon of training?

Means of evaluating employee and supervisor understanding of the program requirements are provided within the training activities (e.g., formal testing, oral questioning, observation, interviews).

7. How are elements of this program incorporated within job-specific training activities?

Elements of this program are included within the training activities associated with job performance and job practices (i.e., supervisor training, craft training, etc.). 


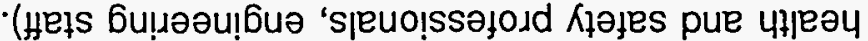

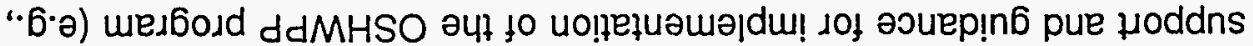

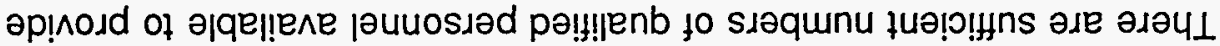

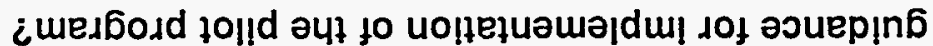

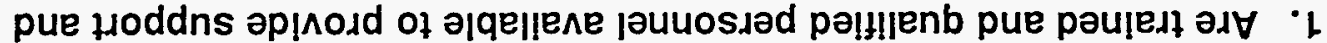

Stey 110504

5

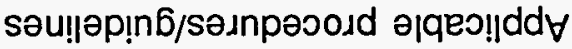

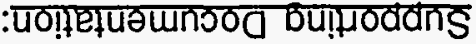

'spiezey of ajnsodxə әәК이

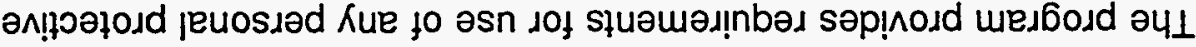

¿mesbosd

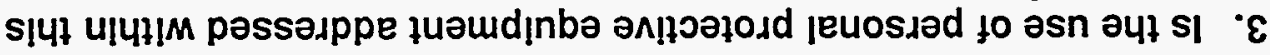

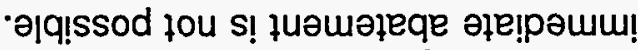

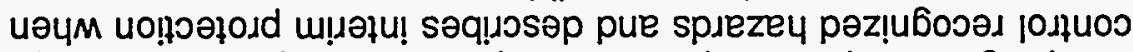

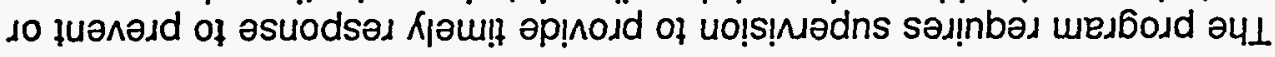

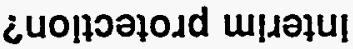

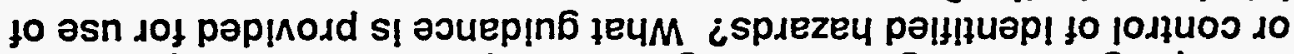

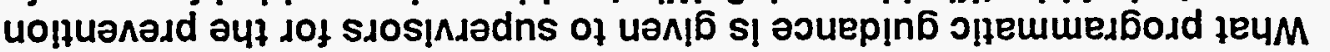

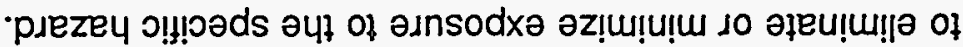

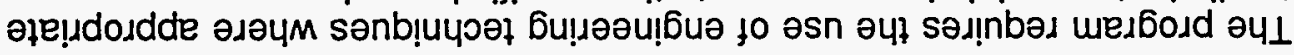

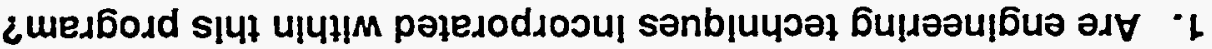

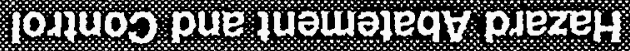

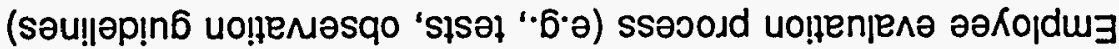

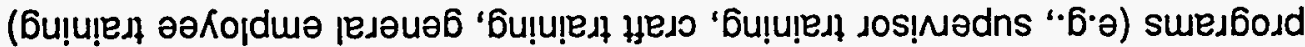

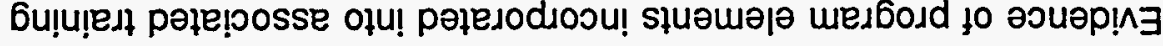

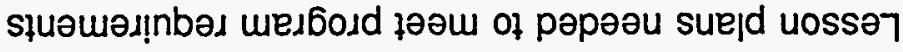

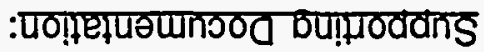




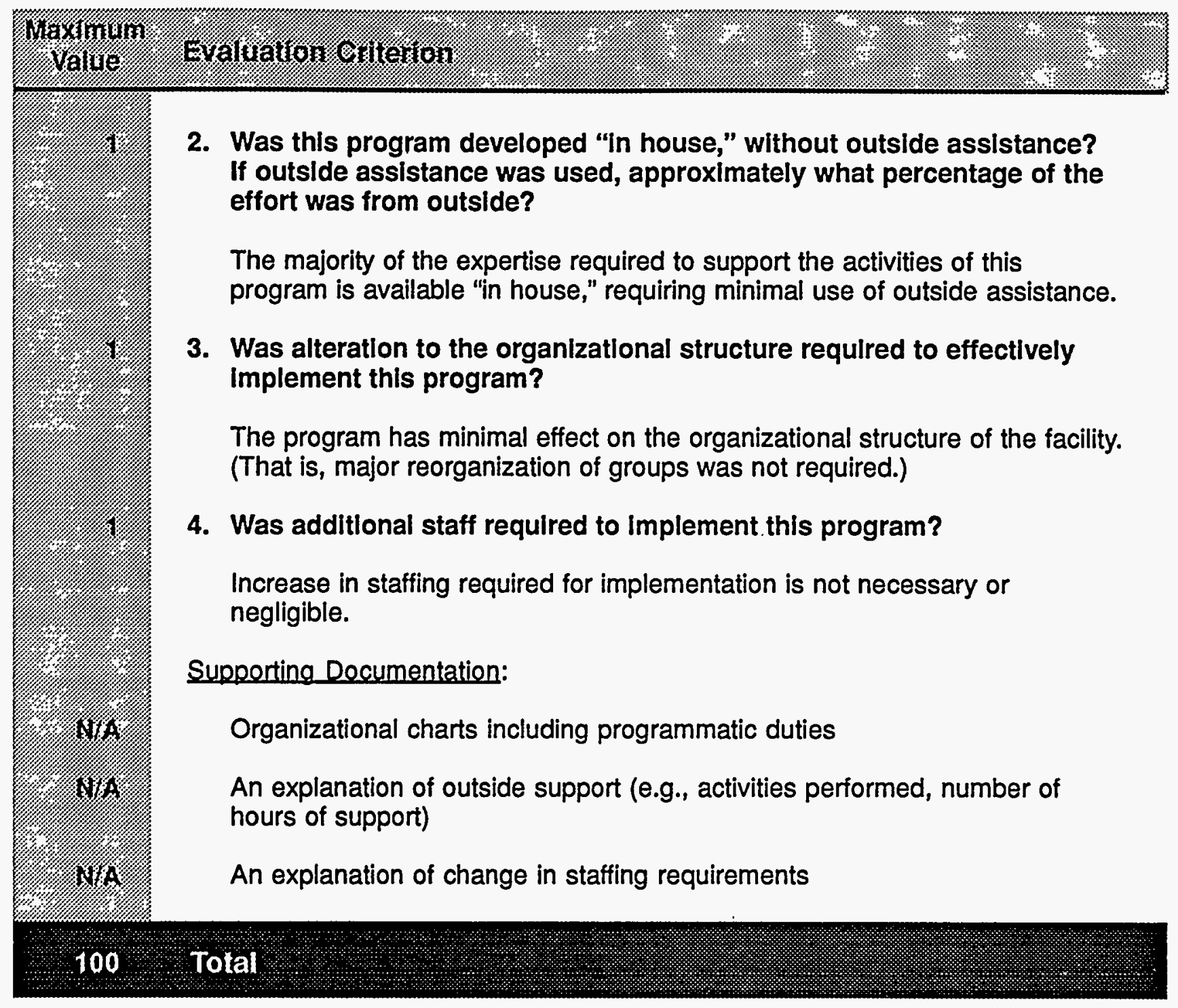




\section{Votes:}

